\title{
A Framework for Identifying Key Decision Makers for Institutional Owner Capital Projects
}

\section{Sushil Brion Shenoy}

Thesis submitted to the faculty of the Virginia Polytechnic Institute and State University in partial fulfillment of the requirements for the degree of

\author{
Master of Science
}

In

\section{Civil Engineering}

Annie R. Pearce, Co-Chair

Michael J. Garvin, Co-Chair

Chris M. Fiori

\author{
August $14^{\text {th }}, 2009$ \\ Blacksburg, VA
}

Keywords: Stakeholders, Key Decision Makers, Framework, Institutional Owner, Construction Project 


\title{
A Framework for Identifying Key Decision Makers for Institutional Owner Capital Projects
}

\author{
Sushil Brion Shenoy
}

\begin{abstract}
The Federal Government spends $\$ 40$ billion dollars a year maintaining its facility portfolio. As a result of the size of investment and current economic conditions, the government and other institutional owners are facing increased pressure to optimize their investment in their portfolios. Green design offers a way for owners to accomplish this. Part of the definition used by the General Services Administration (GSA) for sustainable or green design is minimizing the total life-cycle ownership cost of a facility. Many tools, such as BUILDER or IMPACT, are available to aid institutional owners in this task; however, most do not take into account non-rational behavior since they apply a strict rational logic. In order to develop tools that take non-rational behavior into account, a framework needs to be developed for identifying which actors are worth studying or modeling. This research seeks to fill this gap by developing a framework that can be applied to public sector institutional owners. The framework is based on prior work done in the fields of stakeholder theory and engineering management, and it uses research methodologies from the social sciences as its building blocks.
\end{abstract}




\section{Acknowledgments}

I would like to thank Dr. Pearce, Dr. Garvin, and Dr. Fiori for tirelessly guiding me through this process. For their encouragement, faith in me, and pushing me to excel, I will be forever thankful. I owe a special thanks to Dr. Pearce for pointing out not only the areas where I had strayed but also a way to get back on the right path.

I also would like to thank my family for their support during this endeavor and for teaching me the basic skills that I needed to be successful at it.

Finally, I would like to thank the Cranwells, Sandy Young, Jonathan Buttner, the staff and people of Cru, and all my other friends who encouraged me during the rough times. 


\section{Table of Contents}

List of Tables................................................................................................................. vii

List of Figures............................................................................................................ viii

Chapter 1: Introduction .......................................................................................... 1

1.1 Public Sector Institutional Owners..................................................................... 2

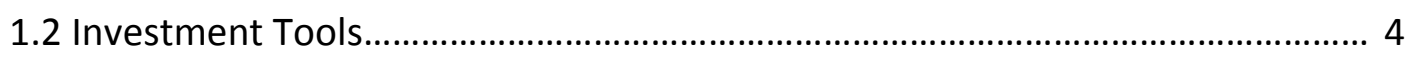

1.3 Costing Methods.............................................................................................. 5

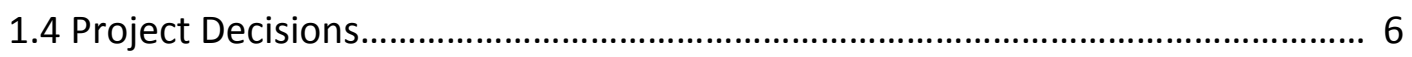

1.5 Research Overview......................................................................................... 9

Chapter 2: Background................................................................................................................... 10

2.1 History of Stakeholder Theory.......................................................................... 10

2.1.1 Definition of a Stakeholder..................................................................... 10

2.1.2 Identification of Stakeholders................................................................ 12

2.2 Application of Stakeholder Theory..................................................................... 14

Chapter 3: Research Design and Methodology........................................................................ 16

3.1 Applying Stakeholder Theory.......................................................................... 16

3.2 Thesis Question................................................................................................. 16

3.3 Question Development.................................................................................. 16

3.3.1 Decision Focus......................................................................................... 16

3.3.2 Key Decision Maker........................................................................... 21

3.4 Framework Development............................................................................. 22

3.5 Protocol Development..................................................................................... 26

3.5.1 Document Review Protocol.................................................................. 27

3.5.2 Semi-Structured Interview Protocol.......................................................... 31

3.5.3 Indirect Observation Protocol............................................................... 33

Chapter 4: Data Collection and Analysis................................................................................. 34

4.1 Document Review Findings............................................................................. 34

4.1.1 Decision Maker Investigation ............................................................... 34 
4.1.2 Candidate Project Identification and Selection................................... 37

4.1.3 Possible Meetings Identification......................................................... 38

4.2 Semi-Structured Interview Findings................................................................ 39

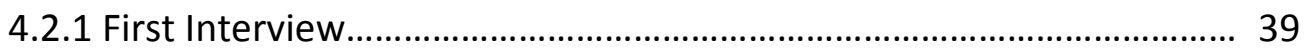

4.2.2 Second and Third Interviews......................................................... 42

4.2.3 Fourth Interview............................................................................. 43

4.3 Indirect Observation Findings......................................................................... 43

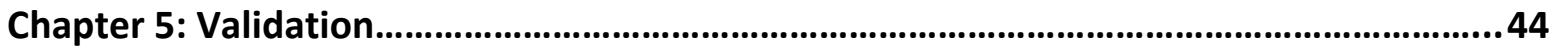

5.1 Document Review Protocol Validation............................................................. 44

5.2 Semi-Structured Interview Protocol Validation................................................. 46

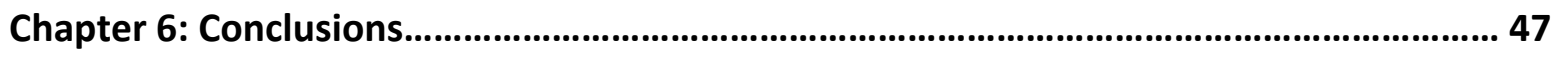

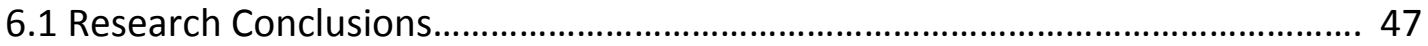

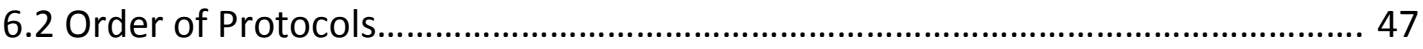

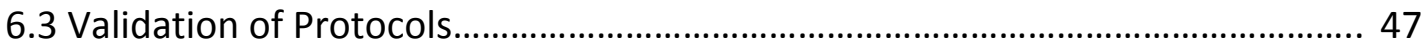

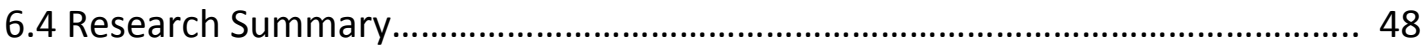

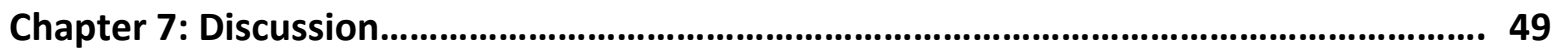

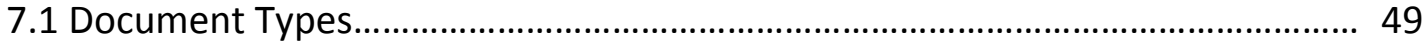

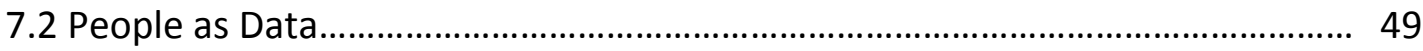

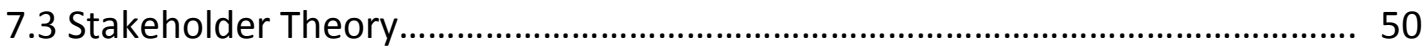

Chapter 8: Limitations, Impacts, and Future Research................................................... 52

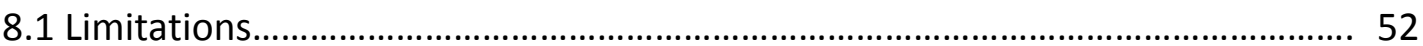

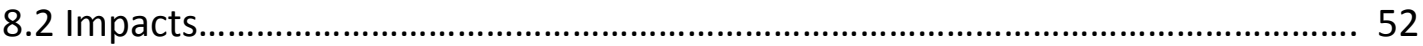

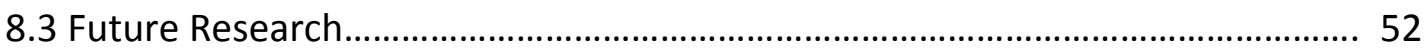

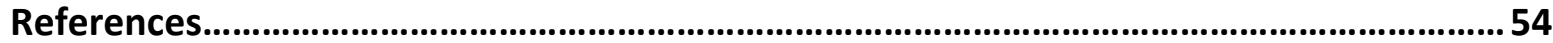

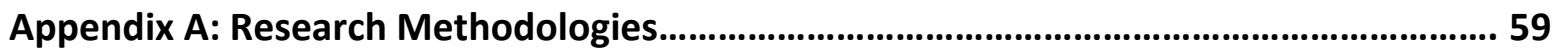

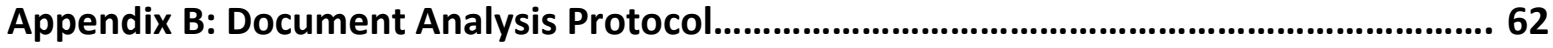

Appendix C: Semi-Structured Interview Protocol................................................................... 66

Appendix D: Indirect Observation Protocol..........................................................................73 


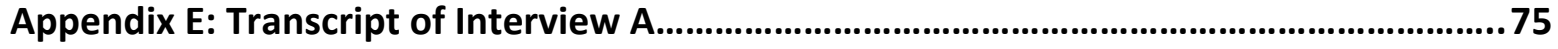

Appendix F: Transcript of Interview B......................................................................... 99

Appendix G: Document Review Project Map...................................................................... 112 


\section{List of Tables}

Table 2.1: Chronology of the Definition of "Stakeholder" (Adapted from Mitchell et al.

$$
\text { 1997) }
$$

Table 3.1: Sample Studies and Topic. 18

Table 3.2: Uniformat II Sample (DOC 1999). 19

Table 4.1: Required Documents (Virginia Tech 2009) 37

Table 4.2: Interview Results. 


\section{List of Figures}

Figure 1.1: US Government Budget Trends (EOPUS 2008)

Figure 1.2: Project Lifecycle (Adapted from Garvin 2003 and Klotz et al. 2007)................. 6

Figure 1.3: Programming Decisions (Adapted from Garvin 2003 and Klotz et al. 2007)...... 7

Figure 1.4: Relationship Complexity in a Construction Project (Pearce et al. 2008).............8

Figure 2.1: Examples of Stakeholder Maps...................................................................... 13

Figure 3.1: High System Cost Chart (Derived from DOC 1999)........................................... 20

Figure 3.2: Framework for Identifying Key Decision Makers (DMs) ................................. 25

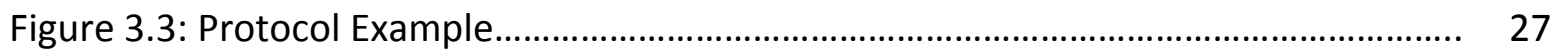

Figure 3.4: Candidate Project Map................................................................... 30

Figure 4.1: Facilities Organization Chart (Virginia Tech 2008).......................................... 35 


\section{Chapter 1: Introduction}

Public organizations and agencies have significant capital in their facility portfolios. The federal government, for example, has over 500,000 facilities in its portfolio with more than $\$ 3$ billion square feet of floor space - an area larger than the state of Nevada (NRC 2004; GSA 2008). In addition, the federal government had $\$ 24$ billion dollars worth of construction put in place in 2008 (Census Bureau 2008). A facility portfolio this large and dynamic comes with a high price tag. The federal government spends almost $\$ 40$ billion per year to maintain its existing portfolio (NRC 2004). Based on the federal government's receipts for the 2008 fiscal year, the $\$ 40$ billion expenditure was about $1.5 \%$ of total receipts (EOPUS 2008). In the federal budgeting process, facility maintenance is considered part of the discretionary spending category (NRC 2008). Figure 1.1 projects that discretionary spending funds are going to decrease substantially over the next several decades.

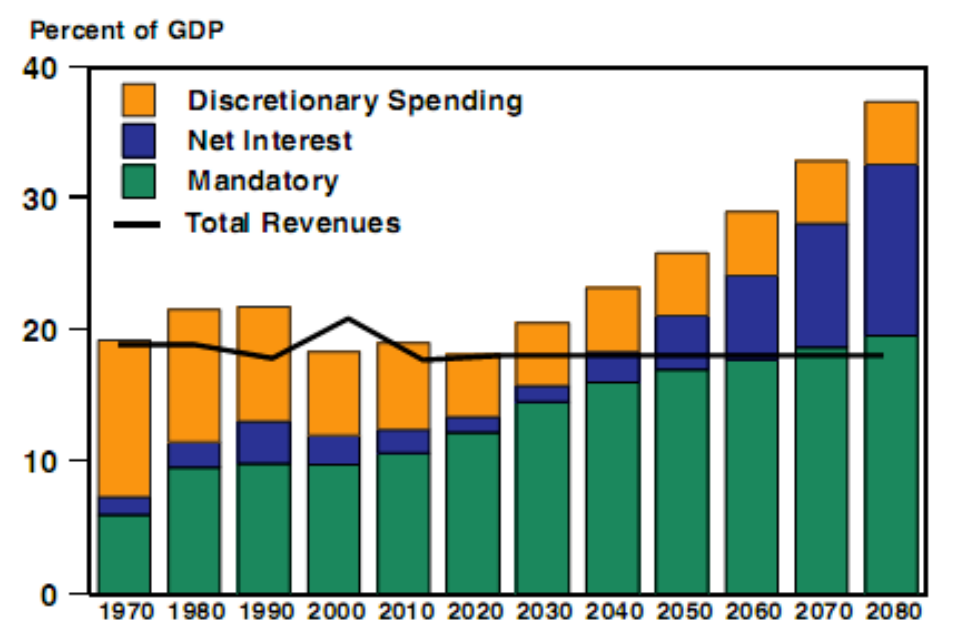

Figure 1.1: US Government Budget Trends (EOPUS 2008)

Furthermore, the General Accounting Office (GAO) has identified federal real property management as a high risk area in 2003 and then again in 2007 (GAO 2003; GAO 2007). A way of dealing with competing stakeholder interests, legal and budgetary disincentives, and better capital planning practices is needed to address the high risk area (GAO 2005). 
One of the ways that public organizations and agencies are trying to deal with these challenges is through the pursuit of sustainable design. The U.S. General Services Administration (GSA) defines sustainable design as the pursuit of the following five goals (GSA 2008):

1) Using an integrated team approach to design, construct, and operate its buildings

2) Reducing the total life-cycle ownership cost of facilities

3) Improving energy efficiency, water conservation, and reducing material consumption

4) Providing safe, healthy, and productive built environments

5) Promoting excellence in environmental stewardship

This research focuses on aiding public sector institutional owners in achieving the second goal of sustainable design as defined by the GSA. To achieve this, who public sector institutional owners are and a metric for measuring the total life-cycle ownership cost of a facility needs to be developed.

\subsection{Public Sector Institutional Owners}

There is no generally accepted definition for what a public sector institutional owner is among construction scholars. Public sector simply refers to the government sector as opposed to the private sector; therefore, the key words for this classification are "institutional owner". The rest of this paper will use "institutional owner" to represent public sector institutional owners.

A search conducted on June $13^{\text {th }}, 2009$, of all the articles in the library of the American Society of Civil Engineers (ASCE) yields no results for the keywords "Institutional Owner". Similarly, a search using the same keywords on the same day in Engineering Village, a database that combines Compendex, Ei Backfile, Inspec Archive, and NTIS databases into one database, returns only two documents neither of which is related to construction. Science Direct and Scirus both return between 150 and 500 records, but none of the articles address institutional owners in a construction sense. They focus on institutional owners as investors (Kane and Velury 2004; Ljungqvist et al. 2007; Matvos and Ostrovsky 2008); therefore, the researcher proposes that the following characteristics be used to define an institutional owner:

1) Assets that are not readily traded 
2) Some type of standardized procurement procedure

3) An in-house construction department

4) Several capital projects being pursued concurrently

5) Projects at different stages of development

6) Assets which have 50+ year lifecycles

These characteristics were identified through discussion among the researcher's peers, the researcher's own experience working for institutional owners, and discussions with experts in the fields of facility management and sustainability (Garvin, M., Pearce, A., and Fiori, C., committee meeting, February 2009). Examples of public sector institutional owners that meet these criteria and demonstrate the significance of them are the Department of Defense (DOD) and Virginia Tech (VT). The very nature of the missions for both of these organizations makes it difficult to trade their facility assets. An airfield is difficult to sell and universities need the stability of owning their own facilities so they are not affected by the ups and downs of the economy as much. It is critical for them to have standardized procurement procedures because their size and the number of other entities they interact with are way too much for a single person to handle. This fact also necessitates their need for an in-house construction department to manage all these interactions. Institutions such as these do not remain static either. They have to continually change to meet their mission's current or future needs; hence, the characteristics of having several projects being pursued concurrently and at different stages of the project lifecycle. These institutions also have very long life spans. The DOD will be in existence as long as the United States is, and VT will most likely be in existence as long as the state of Virginia is. Since these organizations understand this, their facilities are often designed to last for a very long time. The $50+$ year characteristic simply seeks to capture this long term outlook. For example, most structures that the Federal Emergency Management Agency (FEMA) builds are temporary in nature, and thus would not fit this definition.

These characteristics of institutional owners coupled with the trend shown in Figure 1.1 makes it very important for them to optimize their investment in their facilities. Sustainable design and 
green building offer on way to accomplish this; however, in order to invest in green building, institutional owners need effective tools to help optimize that investment.

\subsection{Investment Tools}

There are tools currently available for optimizing infrastructure investment from a technical performance vs. economic viability standpoint. For example, Liu (2009) developed a parametric model for bridge investment. Keysar and Pearce (2007) identified 275 decision support tools to aid in the green design process. The US Army Corps of Engineers's Construction Engineering Research Laboratory (CERL) has developed several decision support tools. Some of them are as follows (CERLb 2009):

1) BUILDER - stores real property building information and more detailed system inventory is modeled and/or collected which identifies building components and their key life-cycle attributes

2) PAVER - optimizes the use of pavement repair funds via a Pavement Condition Index $(\mathrm{PCl})$

3) HEATER - has condition-prediction models that forecast a heating system's deterioration over time. Based on the comprehensive inspection, maintenance and repair needs can be identified and prioritized.

4) REMR (Repair, Evaluation, Maintenance, and Rehabilitation) - involved in planning and budgeting for maintenance and repair $(M \& R)$ of civil works facilities and equipment

5) IMPACT (Integrated Multi-Year Prioritization and Analysis Tool) - a model that simulates the annual fiscal cycle of work planning/executing and displays building, system, and component conditions up to ten years into the future.

6) RAILER - evaluates railroad track and plans effective, economical railroad track M\&R program while also storing data on railroad track inventory, inspection results, track conditions, M\&R costs and policies, work history, and other essential items.

These tools are designed to optimize the allocation of funds and plan maintenance needs for their respective area. PAVER, for example, is designed, "to aid pavement managers and engineers in the inventory, condition assessment, condition prediction, and long range maintenance planning for pavements (CERLa 2009)." They do not incorporate the actual 
tendencies of the people involved. They evaluate their respective system in terms of what the most rational action would be; however, the actions of public sector institutional owners are not always rational. Rationality is the acceptance of a particular course of action over other alternatives based on a given set of axioms or rules that most people consider sensible (adapted from Goodwin and Wright 2004). A tool is needed that considers the issue of investing in green design from the perspective of the actual actors involved. This tool would need to consider the behavior of the actors themselves in order to capture the non-rational actions. The specific behavior of interest is the decision making tendencies of the actors involved. This raises the question of what types of decisions are important.

\subsection{Costing Methods}

In order to determine whether or not a decision is important, one needs a metric to evaluate decisions with. The most often used metric by institutional owners is cost, and there are several different methods for costing that are commonly used. Methods that consider a lifecycle perspective are life-cycle costing (LCC), total cost assessment (TCA), and total cost of ownership (TCO) (Ellram and Siferd 1998). The differences between these different methods are rather subtle.

Lifecycle costing is defined as the sum total of the direct, indirect, recurring, nonrecurring, and other related costs incurred, or estimated to be incurred, in the design, development, production, operation, maintenance, and support of a major system over its anticipated useful life span (EPA 1995). TCA is defined as the long-term, comprehensive financial analysis of the full range of positive and negative cash flows of an investment. It is the process of primarily integrating environmental costs internal to an organization into the capital budgeting analysis (EPA 1995). TCA can include external costs but primarily focuses on internal ones (EPA 1995). TCO is defined as a dollar per square foot value for facilities that includes all facilities-specific costs associated with construction, preservation, maintenance, and operation of the facility (IFMA et al. 2008).

The biggest distinction between the different methods is that LCC is a subset of both TCO and TCA. TCO and TCA are essentially the same because they both include LCC as a part of their 
scope and try to capture a broader base of costs associated with a capital project. The slight difference between the two is TCA approaches costing from an environmental perspective while TCO leans more to the strictly business side (Beaver 2000). To limit the scope of costs to be considered, this research is going to use TCO as the metric for evaluating decisions. Expanding the costs considered to include environmental and social costs is an area for further research.

In order to use TCO to determine the importance of different decisions, decisions that are made during the lifecycle of a project need to be identified.

\subsection{Project Decisions}

Construction projects have several phases during its lifecycle. Figure 1.2 depicts an example of the phases of a general project's lifecycle. During these phases, decisions are made that will impact the cost of the building.

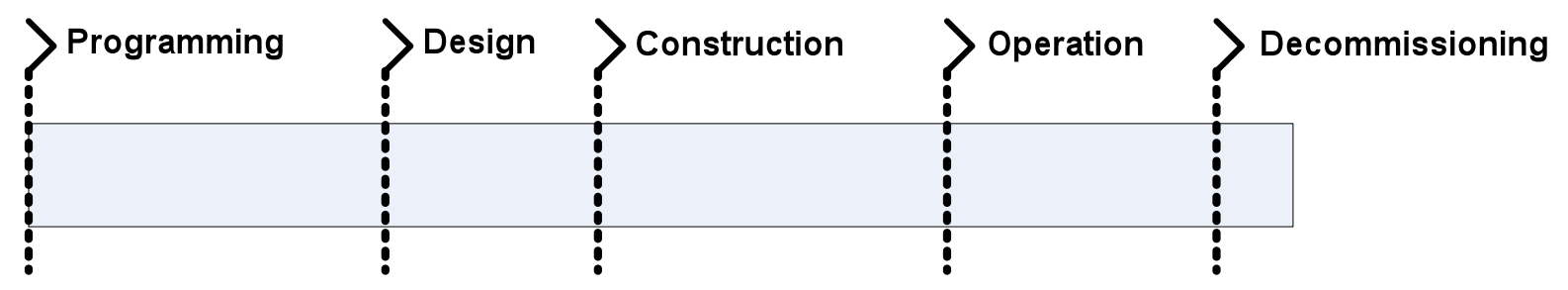

Figure 1.2: Project Lifecycle (Adapted from Garvin 2003 and Klotz et al. 2007)

However, the earlier a decision is made during a project's lifecycle the greater its impact on the project's cost will be. For this reason, this research will focus on decisions made during the programming phase (Hendrickson 2000). There are still many decisions that are made during the programming phase that will affect a project's cost. Figure 1.3 illustrates some of the decisions made during this stage. 


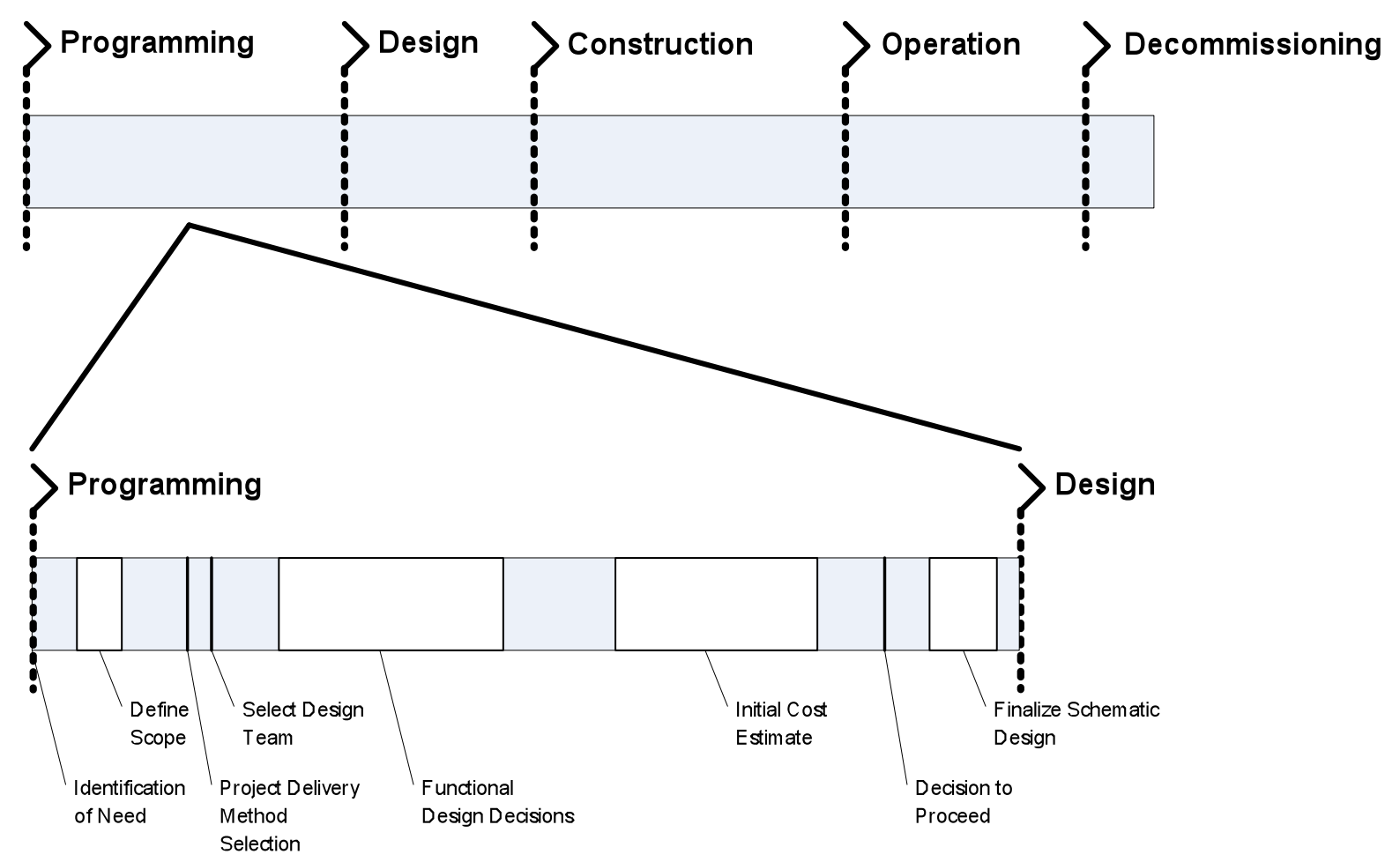

Figure 1.3: Programming Decisions (Adapted from Garvin 2003 and Klotz et al. 2007)

Identification of need, functional design decisions, and project delivery method selection are examples of some of the decisions made during the programming phase (Garvin 2003). The first decision an institutional owner makes is the identification of need. From the identification of need, decisions are made that result in a functional or conceptual design of what the solution to the need would be like. For the project to continue, the owner needs to decide which project delivery method to pursue since the project delivery method will determine the rest of the project's lifecycle path (Garvin 2003). More decisions are then made to bring the project to a schematic design stage. Once a project reaches the schematic design stage, it moves from the programming phase to the design phase.

Institutional owners face another problem in the fact that they have multiple objectives to balance with multiple resource constraints (Hsieh and Liu 1997). For example, an institutional owner may need to balance a larger, higher performing HVAC system with the desire of occupants to have a skylight. These multiple objectives stem from the variety of people and equipment that a space is designed for and the potential changes the space may undergo 
throughout its lifecycle. Figure 1.4 illustrates the complexity of relationships between different people involved in the development of a facility.

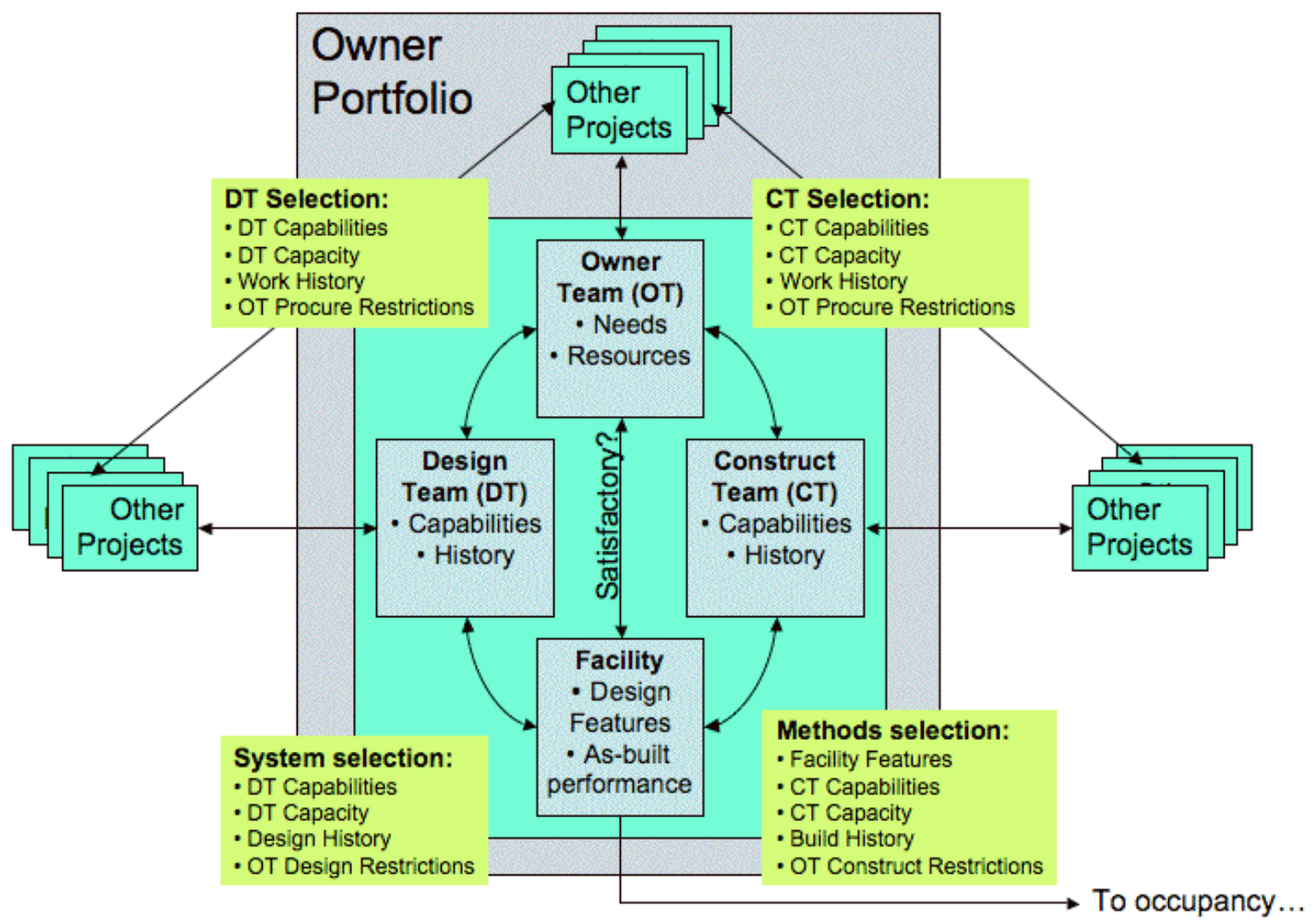

Figure 1.4: Relationship Complexity in a Construction Project (Pearce et al. 2008)

Also, the median lifespan of a commercial facility in the US is between $65-80$ years, and this leads to greater uncertainty in how the space will have to be used over the lifespan (DOE 2008). The longer the lifespan a facility has, the greater the potential for the needs of the occupants to change due in part to advances in technology and expected comfort levels (Brand 1994). For example, in the last 20 years, occupants have gone from only requiring a desk and chair to requiring a computer, fax machine, internet access, and printing capabilities in addition to the original desk and chair. This has resulted in a significant increase in plug loads from the extra equipment and increased HVAC capacity due to increased heat production from the extra equipment.

With all of these decisions being made, the question quickly becomes one of how do you identify which decisions are important? For the purposes of this research, decisions that affect 
the TCO of a project are the most important decisions. Decisions that affect environmental and social attributes of a project are additional areas for further research. With the need for a tool that is capable of capturing non-rational actions, the establishment of TCO as the metric for evaluating decisions, and the identification of decisions that are made during the lifecycle of a project, the last question becomes how does one identify those actors who make the decisions that affect the TCO of a project? Stated simply, how does one identify decision makers that have the greatest impact on TCO? This is the focus of this research.

\subsection{Research Overview}

The aim of this research is to take the first step toward developing a tool that can account for both rational and non-rational actions among institutional owner facility stakeholders:

identifying who is a key stakeholder. This research will establish what makes a stakeholder "key" and also develops a framework for identifying these "key" stakeholders. Since TCO is the metric used by the GSA to achieve green design, key stakeholders will be ones that have the greatest impact on a project's TCO.

The following chapters of this thesis describe the research undertaken to achieve this aim. Chapter 2 presents an overview and analysis of seminal work in the field of stakeholder theory to establish the background and point of departure of the work. Chapter 3 develops the methodology and instruments used in this research for identifying key decision makers. Chapter 4 reports the data and findings from applying the instruments developed in the previous chapter. The thesis concludes with a discussion of the validation techniques, the conclusions, the limitations, and the areas of future research for this research. 


\section{Chapter 2: Background}

Identifying important actors or key decision makers in an organization is the subject of stakeholder theory. This chapter provides a basic introduction to stakeholder theory. The history of stakeholder theory will be discussed and a recent example of its application will be discussed in this chapter.

\subsection{History of Stakeholder Theory}

\subsubsection{Definition of a Stakeholder}

Stakeholder theory has been present in business and academia for more than forty years (Grossi 2003). One of the key questions that stakeholder theory tries to solve is "Who are stakeholders?" aka, "How do you identify them (Grossi 2003)?" In order to answer this question, what a stakeholder is needs to be defined.

Conceptually, stakeholders are similar to stockholders. Just as a stockholder financially and economically supports an organization, a stakeholder also supports an organization. The stakeholder supports an organization not only financially or economically but also supports the very life or continuity of an enterprise (Grossi 2003). Since the concept of a stakeholder is so broad, it is difficult to define. Many scholars have defined it in terms of their particular field of study. Mitchell, Agle, and Wood (1997) presented a chronology of these types of definitions. Table 2.1 is a summary of their chronology.

Table 2.1: Chronology of the Definition of "Stakeholder" (Adapted from Mitchel et al. 1997)

\begin{tabular}{|l|l|l|}
\hline Date & Author(s) & Definition \\
\hline 1963 & Stanford Memo & $\begin{array}{l}\text { those groups without whose support the organization would } \\
\text { cease to exist (cited in Freeman \& Reed, 1983, and Freeman, } \\
1984 \text { ) }\end{array}$ \\
\hline 1974 & Rhenman & $\begin{array}{l}\text { are depending on the firm in order to achieve their personal } \\
\text { goals and on whom the firm is depending for its existence } \\
\text { (cited in Nasi, 1995) }\end{array}$ \\
\hline
\end{tabular}




\begin{tabular}{|c|c|c|}
\hline 1971 & $\begin{array}{l}\text { Ahlstedt \& } \\
\text { Jahnukainen }\end{array}$ & $\begin{array}{l}\text { driven by their own interests and goals are participants in a } \\
\text { firm, and thus depending on it and whom for its sake the firm } \\
\text { is depending (cited in Nasi, 1995) }\end{array}$ \\
\hline 1983 & Freeman \& Reed & $\begin{array}{l}\text { Wide: "can affect the achievement of an organization's } \\
\text { objectives or who is affected by the achievement of an } \\
\text { organization's objectives"; } \\
\text { Narrow: "on which the organization is dependent for its } \\
\text { continued survival" }\end{array}$ \\
\hline 1984 & Freeman & $\begin{array}{l}\text { can affect or is affected by the achievement of the } \\
\text { organization's objectives }\end{array}$ \\
\hline 1987 & Freeman \& Gilbert & can affect or is affected by a business \\
\hline 1987 & Cornell \& Shapiro & "claimants" who have "contracts" \\
\hline 1988 & Evan \& Freeman & have a stake in or claim on the firm \\
\hline 1988 & Evan \& Freeman & $\begin{array}{l}\text { benefit from or are harmed by, and whose rights are violated } \\
\text { or respected by, corporate actions }\end{array}$ \\
\hline 1988 & Bowie & without whose support the organization would cease to exist \\
\hline 1989 & Alkhafaji & groups to whom the corporation is responsible \\
\hline 1989 & Carroll & $\begin{array}{l}\text { "asserts to have one or more of these kinds of stakes"- } \\
\text { "ranging from an interest to a right (legal or moral) to } \\
\text { ownership or legal title to the company's assets or property" }\end{array}$ \\
\hline 1990 & Freeman \& Evan & contract holders \\
\hline 1991 & Thompson et al. & in "relationship with an organization" \\
\hline 1991 & Savage et al. & $\begin{array}{l}\text { have an interest in the actions of an organization and ... the } \\
\text { ability to influence it }\end{array}$ \\
\hline 1992 & Hill \& Jones & $\begin{array}{l}\text { constituents who have a legitimate claim on the firm ... } \\
\text { established through the existence of an exchange relationship } \\
\text { who supply "the firm with critical resources (contributions) } \\
\text { and in exchange each expects its interests to be satisfied (by } \\
\text { inducements)" }\end{array}$ \\
\hline 1993 & Brenner & $\begin{array}{l}\text { having some legitimate, non-trivial relationship with an } \\
\text { organization [such as] exchange transactions, action impacts, } \\
\text { and moral responsibilities }\end{array}$ \\
\hline 1993 & Carroll & $\begin{array}{l}\text { "asserts to have one or more of the kinds of stakes in } \\
\text { business"-may be affected or affect ... }\end{array}$ \\
\hline 1994 & Freeman & participants in "the human process of joint value creation" \\
\hline 1994 & Wicks et al. & $\begin{array}{l}\text { interact with and give meaning and definition to the } \\
\text { corporation }\end{array}$ \\
\hline 1994 & Langtry & $\begin{array}{l}\text { the firm is significantly responsible for their well-being, or } \\
\text { they hold a moral or legal claim on the firm }\end{array}$ \\
\hline
\end{tabular}




\begin{tabular}{|c|c|c|}
\hline 1994 & Starik & $\begin{array}{l}\text { "can and are making their actual stakes known"-"are or might } \\
\text { be influenced by, or are or potentially are influencers of, } \\
\text { some organization" }\end{array}$ \\
\hline 1994 & Clarkson & $\begin{array}{l}\text { "bear some form of risk as a result of having invested some } \\
\text { form of capital, human or financial, something of value, in a } \\
\text { firm" or "are placed at risk as a result of a firm's activities" }\end{array}$ \\
\hline 1995 & Clarkson & $\begin{array}{l}\text { have, or claim, ownership, rights, or interests in a corporation } \\
\text { and its activities }\end{array}$ \\
\hline 1995 & Nasi & interact with the firm and thus make its operation possible \\
\hline 1995 & Brenner & $\begin{array}{l}\text { are or which could impact or be impacted by the } \\
\text { firm/organization }\end{array}$ \\
\hline 1995 & $\begin{array}{l}\text { Donaldson \& } \\
\text { Preston }\end{array}$ & $\begin{array}{l}\text { persons or groups with legitimate interests in procedural } \\
\text { and/or substantive aspects of corporate activity }\end{array}$ \\
\hline
\end{tabular}

Probably the most widely accepted definition for stakeholder was presented by R. Edward Freeman (1984) in his sentinel work, Strategic Management: A Stakeholder Approach. He defines it as, "any group or individual who can affect or is affected by the achievement of the firm's objectives." In the context of this research, the "firm" is a public sector institutional owner, and the objective of the owner is minimizing the TCO for their facility. The "affect or is affected by" portion of the definition requires some interpretation. The word "affect" here indicates that there are different levels of impact that a group or individual experiences. For example, a student will have relatively low impact on the design of a faculty's office, but the faculty member will have a much higher impact or will be impacted much more than the student. Now that the general definition and concept of who a stakeholder is has been established, the next question is how does stakeholder theory identify them?

\subsubsection{Identification of Stakeholders}

The definition discussed above makes the identification of stakeholders rather challenging because of the breadth of the definition's scope. Virtually any entity could claim to be affected by the achievement of a firm's or institutional owner's goals and therefore claim to be a stakeholder. This issue is further exacerbated by the complex nature of institutional owners due to the number of internal and external relationships that they have. To address this problem, some scholars have developed frameworks for identifying and classifying stakeholders. 
One manifestation of these frameworks is mapping techniques. Commonly used mapping techniques map stakeholder interest vs. power or stakeholder interest vs. attitude (MurryWebster and Simon 2006). Figure 2.1 illustrates maps such as these.
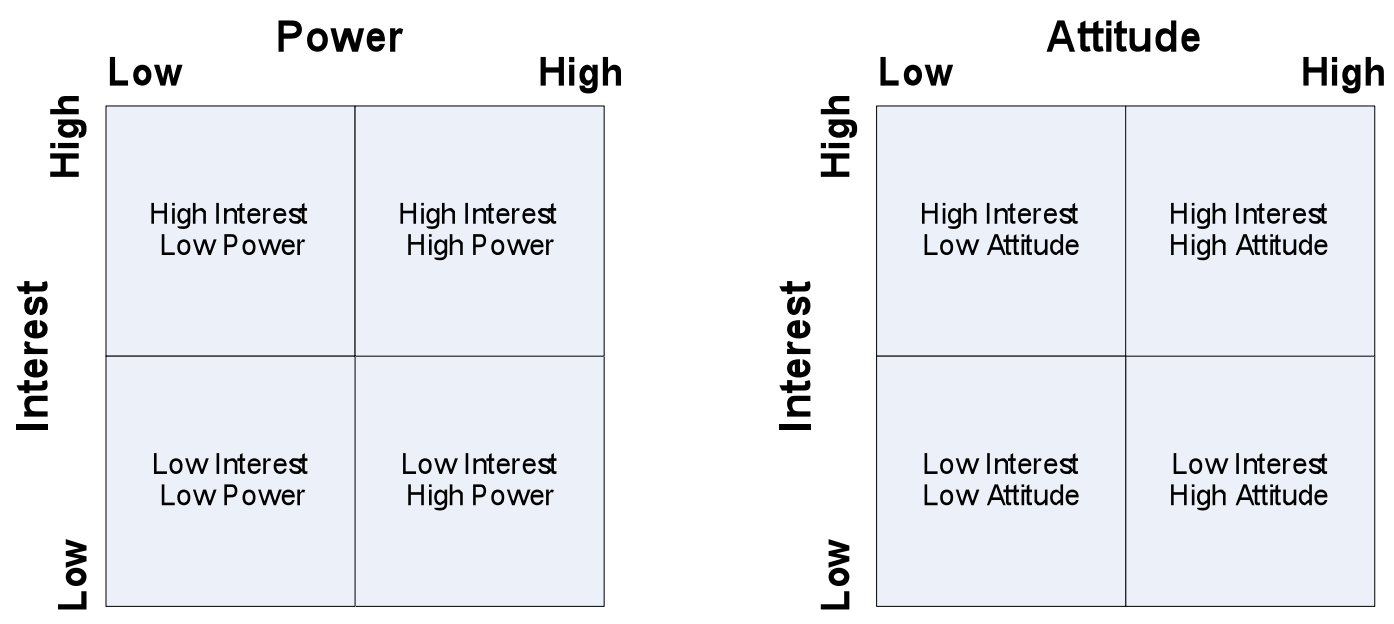

Figure 2.1: Examples of Stakeholder Maps

High or low interest is an indication of the likelihood for a particular stakeholder to be or become involved in the operation being undertaken by the institutional owner. Power is an indicator of the level of influence a particular stakeholder has. The influence could have many different forms such as legal right, positional power, or control of resource allocation. Attitude is an indicator of the disposition of the stakeholder, either for or against (Murry-Webster and Simon 2006). There are also three dimensional versions of stakeholder maps that combine the two illustrated above (Murry-Webster and Simon 2006).

Mitchell, Agle, and Wood (1997) propose a different framework for stakeholder identification. Their framework also utilizes three different attributes to identify stakeholders. The three attributes that they identified are power, legitimacy, and urgency. Power is the ability of a stakeholder to impose its will. For example, a CEO has power due to their position. Legitimacy is defined as, "a generalized perception or assumption that the actions of an entity are desirable, proper, or appropriate within some socially constructed system of norms, values, beliefs, and definitions" (Mitchell et al. 1997). For example, a stakeholder with a legitimate claim would be one who proposed the use of green products over conventional ones because using green products is 
generally considered desirable. Urgency is present when two conditions are met. The first is, "...when a relationship or claim is of a time-sensitive nature", and the second is, "...when that relationship or claim is important or critical to the stakeholder operations and/or strategies" (Mitchell et al. 1997). For example, a HVAC subcontractor may run into a conflict with the steel frame of a building. The subcontractor needs to get this conflict resolved quickly because the other trades cannot complete their work until he has. In this case, the HVAC subcontractor has a time critical need, and its resolution is critical to the completion of the project.

The attributes of power, legitimacy, and urgency are independent of one another. A stakeholder can have any combination of these different attributes at any given time. They form a dynamic system of attributes that will change as the goals of the firm or institutional owner change or are achieved.

\subsection{Application of Stakeholder Theory}

Grossi (2003) applied Mitchell, Agle, and Wood's framework for stakeholder identification to a firm named Payload Systems Incorporated. It is a small aerospace company in Cambridge, MA, that specializes in providing engineering support for manned space flight. Payload Systems' typical client is a researcher who has developed a new technology for space use. They would then help the researcher find funding to test it and fabricate the design.

Grossi begins identifying stakeholders by defining a system level value for Payload Systems. A system level value is the objective of the organization. When defining a system level value, Grossi suggests the grammatical construction "To [statement of overall intent] by [statement of process or behavior]." For example, a system level value for the United States Postal Service could be "to maximize customer satisfaction by efficiently processing the mail". A system level value such as this can then be used to identify stakeholders in meeting this system value. It also provides system boundaries for the research being conducted.

The next step that Grossi took was to identify a focal organization. The focal organization is some entity in the enterprise that is the starting point for identifying stakeholders. It is the central entity for the analysis being conducted. In a small company such as Payload Systems, the whole company is the focal organization; however, in larger organizations such as the US 
Air Force, the focal organization would be a sub-unit of the whole organization. For example, the medical squadron would not necessarily be a stakeholder in the development of a new aircraft.

With the system level value and focal organization identified, Grossi began identifying potential stakeholders. His method for identifying stakeholders was surveys, interviews, observations, and reviewing archival records. He identified these techniques based on a book by Wasserman and Faust (1994) that summarized different social network analysis methods. He started his work with Payload Systems by conducting a series of interviews with the CEO of the focal organization. The interviews were designed to analyze the organization in depth to uncover as many tacit or hidden stakeholders as possible. Other related external stakeholders were identified through reviewing the web sites of organizations associated with NASA and NASA's website itself. Grossi then went on to assign each of the stakeholders a level of salience based on a combination of ratings given to each stakeholder's level of power, legitimacy, and urgency.

The basic steps that Grossi used in his work are as follows:

1) Identify the system level value

2) Identify the focal organization

3) Identify the stakeholders using surveys, interviews, observation, and archival record analysis

Grossi provides a good example of applying stakeholder theory to a manufacturing type organization and identifies the stakeholders in that context; however, an example of applying stakeholder theory in the context of the construction industry is lacking. 


\section{Chapter 3: Research Design and Methodology}

The research will use Grossi's work as a starting point and apply it to a construction project. This chapter will first follow Grossi's basic steps to define the context in which this research is being carried out, and then use it as a departure point for the specific question addressed by this research. Subsequently, the development of the specific methodology and tools used to answer the research question will be developed.

\subsection{Applying Stakeholder Theory}

Following Grossi's example, three steps need to be taken to apply stakeholder theory to a construction project. Identifying the system level value, the focal organization, and the stakeholders are the three steps. The system level value for this research will be to minimize the total cost of ownership for a construction project by identifying decision makers as a first step towards creating a tool that optimizes TCO. The focal organization for this research is going to be the Facilities Department at Virginia Tech since they are responsible for all construction projects at Virginia Tech. Virginia Tech was selected as the overall organization of study because it meets the qualifications of an institutional owner stated in the previous chapters. Its facility assets are not readily traded. It has standards for procurement which will be discussed later in the chapter. It has an in-house construction department that overseas multiple projects at different stages of development, and its' facilities have a design life of 75 to 100 years. This leaves the identification of stakeholders as the last step to be addressed. It is this step that is the subject of the question this research seeks to address.

\subsection{Thesis Question}

Who are the key decision makers (stakeholders) that impact a construction project's TCO, and what framework should be used to identify them?

\subsection{Question Development}

\subsubsection{Decision Focus}

In order to pursue this research question, the decisions of a key decision maker need to be defined. As previously stated, key decisions for this research are ones that affect TCO during the 
programming phase of a project. Further, Boussabaine and Kirkham (2004) summarize the key decisions that are made during the conceptual development or programming phase as decisions that may involve the following:

- Substructure

- Structural framework

- Upper floors

- Environmental services

- Life expectancy of the major components

- Frequency of replacement and maintenance through the economic life of the facility

- Internal finishes/ partitions/ doors/ stairs/ fittings

- External shell/ walls/ windows/doors

- Roofing systems

- External works

- Environmental impacts

- Operational

- Production

- Disposal

The researcher was not able to find a study that considered all of these decisions from a TCO perspective. However, Table 3.1 summarizes a sample of studies that looked at a single system or building material. All of these studies considered their respective topic from a lifecycle perspective (Ehlen 1997; Gurung and Mahendran 2002; Johansson 2009; Kosareo and Ries 2007). Unfortunately, these studies did not have enough common ground to build a table comparing the relative TCO impacts. 
Table 3.1: Sample Studies and Topic

\begin{tabular}{|l|l|}
\hline Author & Study Topic \\
\hline Ehlen 1997 & $\begin{array}{l}\text { Fiber-reinforced polymer bridge } \\
\text { decks }\end{array}$ \\
\hline $\begin{array}{l}\text { Gurung and Mahendran } \\
2002\end{array}$ & Steel portal frame building systems \\
\hline Johansson 2009 & HVAC systems \\
\hline Kosareo and Ries 2007 & Green roofs vs. conventional roofs \\
\hline
\end{tabular}

However, a study done by the US Department of Commerce (DOC) (1999) of the UniFormat II system estimated the total installed cost of an eight story office building using the building system approach inherent to the UniFormat system. UniFormat II decomposes a building into its individual systems as seen in Table 3.2. The study also included an estimation of the contractor's profit margin in the total installed cost calculations. This study also does not consider the building systems from a lifecycle perspective, but it does calculate the cost differences between the different building systems and captures most of the key decisions that Boussabaine and Kirkham (2004) identified. Since this study does these two things, it has sufficient information to provide a proof of concept. Future research will need to expand this study to a TCO perspective. 
Table 3.2: UniFormat II Sample (DOC 1999)

ASTM Uniformat II Classification for Building Elements (E1557-97)

\begin{tabular}{|c|c|c|}
\hline $\begin{array}{l}\text { Level } 1 \\
\text { Major Group Elements }\end{array}$ & $\begin{array}{c}\text { Level } 2 \\
\text { Group Elements }\end{array}$ & $\begin{array}{l}\text { Level } 3 \\
\text { Individual Elements }\end{array}$ \\
\hline \multirow[t]{2}{*}{ A SUBSTRUCTURE } & A10 Foundations & $\begin{array}{ll}\text { A1010 } & \text { Standard Foundations } \\
\text { A1020 } & \text { Special Foundations } \\
\text { A1030 } & \text { Slab on Grade }\end{array}$ \\
\hline & A20 Basement Construction & $\begin{array}{ll}\text { A2010 } & \text { Basement Excavation } \\
\text { A2020 } & \text { Basement Walls }\end{array}$ \\
\hline \multirow[t]{3}{*}{ B SHELL } & B10 Superstructure & $\begin{array}{ll}\text { B1010 } & \text { Floor Construction } \\
\text { B1020 } & \text { Roof Construction } \\
\end{array}$ \\
\hline & B20 Exterior Enclosure & $\begin{array}{ll}\text { B2010 } & \text { Exterior Walls } \\
\text { B2020 } & \text { Exterior Windows } \\
\text { B2030 } & \text { Exterior Doors } \\
\end{array}$ \\
\hline & B30 Roofing & $\begin{array}{ll}\text { B3010 } & \text { Roof Coverings } \\
\text { B3020 } & \text { Roof Openings }\end{array}$ \\
\hline \multirow[t]{3}{*}{$\begin{array}{ll}\text { C } & \text { INTERIORS }\end{array}$} & C10 Interior Construction & $\begin{array}{ll}\text { C1010 } & \text { Partitions } \\
\text { C1020 } & \text { Interior Doors } \\
\text { C1030 } & \text { Fittings } \\
\end{array}$ \\
\hline & C20 Stairs & $\begin{array}{ll}\text { C2010 } & \text { Stair Construction } \\
\text { C2020 } & \text { Stair Finishes } \\
\end{array}$ \\
\hline & C30 Interior Finishes & $\begin{array}{ll}\text { C3010 } & \text { Wall Finishes } \\
\text { C3020 } & \text { Floor Finishes } \\
\text { C3030 } & \text { Ceiling Finishes }\end{array}$ \\
\hline \multirow[t]{5}{*}{ D SERVICES } & D10 Conveying & $\begin{array}{ll}\text { D1010 } & \text { Elevators \& Lifts } \\
\text { D1020 } & \text { Escalators \& Moving Walks } \\
\text { D1090 } & \text { Other Conveying Systems } \\
\end{array}$ \\
\hline & D20 Plumbing & $\begin{array}{ll}\text { D2010 } & \text { Plumbing Fixtures } \\
\text { D2020 } & \text { Domestic Water Distribution } \\
\text { D2030 } & \text { Sanitary Waste } \\
\text { D2040 } & \text { Rain Water Drainage } \\
\text { D2090 } & \text { Other Plumbing Systems } \\
\end{array}$ \\
\hline & D30 HVAC & $\begin{array}{ll}\text { D3010 } & \text { Energy Supply } \\
\text { D3020 } & \text { Heat Generating Systems } \\
\text { D3030 } & \text { Cooling Generating Systems } \\
\text { D3040 } & \text { Distribution Systems } \\
\text { D3050 } & \text { Terminal \& Package Units } \\
\text { D3060 } & \text { Controls \& Instrumentation } \\
\text { D3070 } & \text { Systems Testing \& Balancing } \\
\text { D3090 } & \text { Other HVAC Systems \& } \\
& \text { Equipment } \\
\end{array}$ \\
\hline & D40 Fire Protection & $\begin{array}{ll}\text { D4010 } & \text { Sprinklers } \\
\text { D4020 } & \text { Standpipes } \\
\text { D4030 } & \text { Fire Protection Specialties } \\
\text { D4090 } & \text { Other Fire Protection Systems }\end{array}$ \\
\hline & D50 Electrical & $\begin{array}{ll}\text { D5010 } & \text { Electrical Service \& } \\
& \text { Distribution } \\
\text { D5020 } & \text { Lighting and Branch Wiring } \\
\text { D5030 } & \text { Communications \& Security } \\
\text { D5090 } & \text { Other Electrical Systems } \\
\end{array}$ \\
\hline \multirow[t]{2}{*}{$\begin{array}{l}\text { E EQUIPMENT \& } \\
\text { FURNISHINGS }\end{array}$} & E10 Equipment & $\begin{array}{ll}\text { E1010 } & \text { Commercial Equipment } \\
\text { E1020 } & \text { Institutional Equipment } \\
\text { E1030 } & \text { Vehicular Equipment } \\
\text { E1090 } & \text { Other Equipment } \\
\end{array}$ \\
\hline & E20 Furnishings & $\begin{array}{ll}\text { E2010 } & \text { Fixed Furnishings } \\
\text { E2020 } & \text { Movable Furnishings } \\
\end{array}$ \\
\hline \multirow[t]{2}{*}{$\begin{array}{ll}\text { F } & \text { SPECIAL CONSTRUCTION } \\
& \& \text { DEMOLITION }\end{array}$} & F10 Special Construction & $\begin{array}{ll}\text { F1010 } & \text { Special Structures } \\
\text { F1020 } & \text { Integrated Construction } \\
\text { F1030 } & \text { Special Construction Systems } \\
\text { F1040 } & \text { Special Facilities } \\
\text { F1050 } & \begin{array}{l}\text { Special Controls and } \\
\text { Instrumentation }\end{array} \\
\end{array}$ \\
\hline & $\begin{array}{ll}\text { F20 } & \begin{array}{l}\text { Selective Building } \\
\text { Demolition }\end{array}\end{array}$ & $\begin{array}{ll}\text { F2010 } & \text { Building Elements Demolition } \\
\text { F2020 } & \begin{array}{l}\text { Hazardous Components } \\
\text { Abatement }\end{array}\end{array}$ \\
\hline
\end{tabular}


Another limitation of this study is that it only looks at a single building and building type.

However, it is still sufficient to provide proof of concept for this research since a significant amount of institutional owner facilities could be considered office type facilities. For example, of the new construction the federal government built in 2008 , about one quarter of it was office space alone (Census Bureau 2008). An area of future research is to expand the number of buildings and building types and see if there is a change in the system ranking. Figure 3.1 is the High System Cost Chart (HSCC) that summarizes the UniFormat study's findings.

\section{High System Cost Chart}
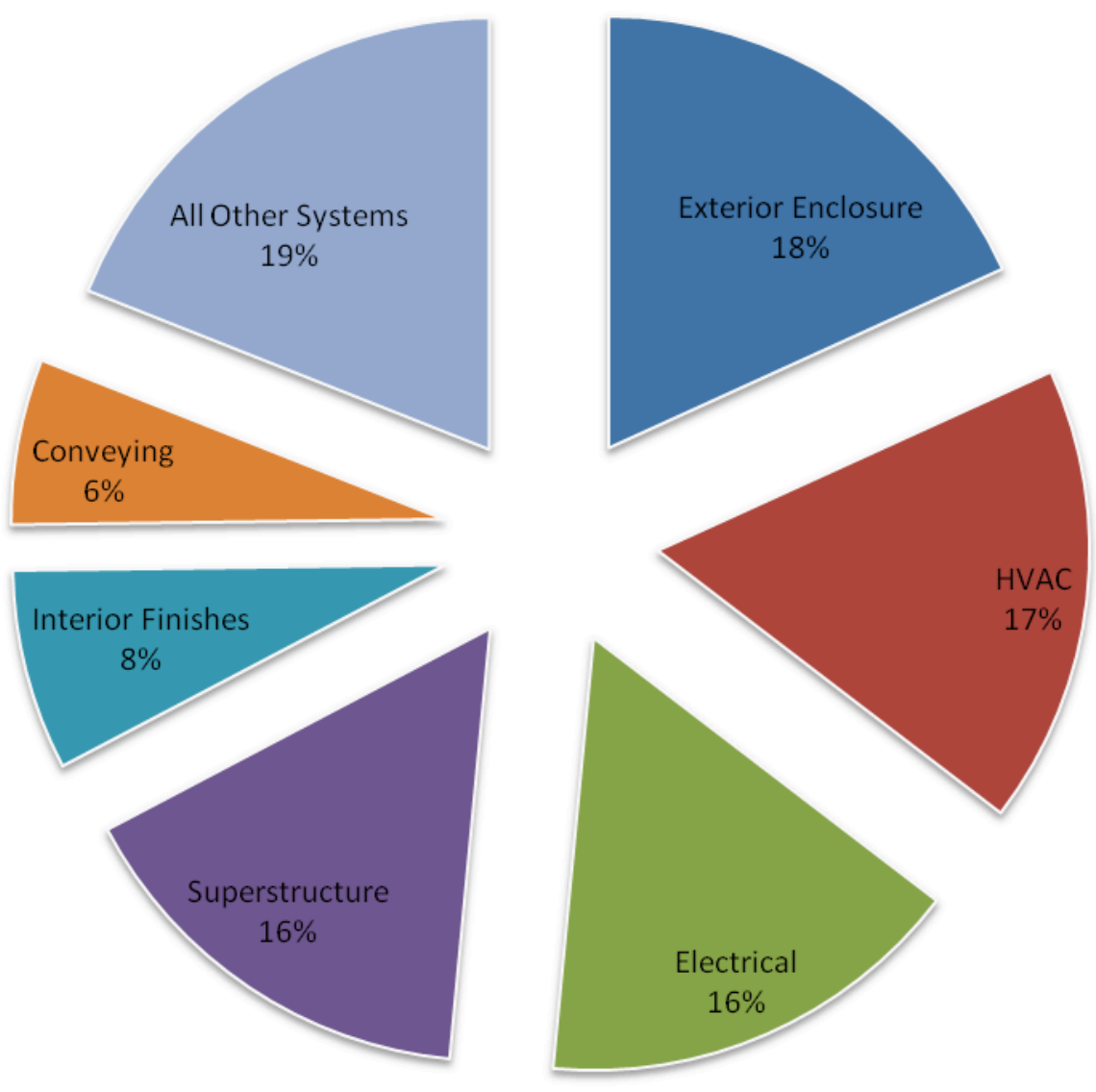

Figure 3.1: High System Cost Chart (Derived from DOC 1999) 
The Department of Commerce study provided the focus for the decisions being considered. Specifically, this research considered UniFormat II building system selection decisions. The next step is to develop a definition for what a "key decision maker" is.

\subsubsection{Key Decision Maker}

A decision maker is someone who makes a decision or decisions, and according to the MerriamWebster dictionary, the word "key" only has one definition when used as an adjective. It means important, fundamental, chief, or pivotal (Merriam-Webster 2009). Therefore, the definition for "key decision maker" for this research is a person or group who act as a single entity whose decisions are considered the most important when considering the selection and characteristics of UniFormat II building systems.

Why is it important to find key decision makers? Why not find every decision maker? For large organizations or projects, it would not be realistic to find every decision maker, and institutional owners by their very nature are large organizations. Therefore by identifying key decision makers, a reasonable approximation of the organization can be attained. Future research should explore the most effective balance between modeling effort involved in representing more individual decision makers vs. improvement in fidelity of model outcomes.

After conducting a literature review, the researcher found that decision makers are typically identified via methods such as "brain storming" (Macal and North 2005, Macal and North 2006). Brain storming has several disadvantages that need to be addressed. The results from a brain storming session are very difficult to replicate even with the same people. There is often a fear of departing from the general consensus of the group, and participants do not always share the same level commitment to the goals of the brain storming session (Isaksen and Gaulin 2005). However, Wasserman and Faust (1994) summarized some alternative methods that Grossi (2003) then acted upon in his research. He used document analysis, questionnaires, interviews, and observation to identify stakeholders. Some other potential research methodologies are listed in Appendix $A$, but this research will use the methodologies patterned by Grossi and develop a framework from them. The development of such a 
framework to identify key decision makers for capital projects of institutional owners is the contribution of this research.

\subsection{Framework Development}

The next task was to determine the order to employ each methodology thereby developing the framework for identifying key decision makers. Since document analysis does not require stakeholder interaction or Institutional Review Board (IRB) review, the best place to start the framework is with document analysis; and then based on data collected from the document analysis, proceed from there to the next method. The anticipated documents the researcher hopes to collect are organizational charts, turnover documentation, project documentation, and other related documents that will indicate who is responsible for different systems.

After document review, the question is which method to use next? The subsequent methods for the framework need to continue collecting the initial data and also provide a way to validate the data. An initial data collection method will need to have a moderate to high level of

flexibility due to the lack of knowledge of organizational practices on the part of the researcher. A validation method will need to establish convergence of data from different sources. Along with the above requirements, an overall objective in selecting methodologies for the framework is to minimize researcher effort.

Validation of data can be accomplished in different ways. Plucker (1990) identifies the following methods:

1) Member checks - having study participants review conclusions

2) Saturation - developing new understandings from the inquiry process

3) Triangulation - finding at least three sources to corroborate a viewpoint

Member checks would not validate the data collected in this research because the data is of a discrete nature. For instance, it would not be very meaningful for a study participant to verify the fact that they identified the project manager as a key decision maker. This form of validation is suited better for research such as investigating consumer opinion on product selection. Saturation is also not suited for validating this research because it leaves it up to the 
researcher's discretion to determine when "saturation" or "no more new information is available" has occurred (Morse 1995). This is a cause for concern when only one researcher is conducting the work. Triangulation is established when three or more unique sources of information arrive at the same result. For example, if three or more people who had not communicated to one another all say that a mutual friend has a particular character flaw, it is very likely that this friend does indeed have a character flaw. Therefore, this research will use triangulation as its validation method.

Questionnaires, interviews, and observation are the remaining methods used by Grossi. Of these, questionnaires were discarded because for a single project there are not enough potential decision makers to be able to afford the low response rate typical of surveys. Therefore, interviews will be used as the second step in the framework since they can be used as either primary data collection or validation. A semi-structured interview has the flexibility to allow the researcher to guide the course of the interview to where it needs to or to explore a related area that presented itself during the interview. Interviews also present a potential validation opportunity if convergence is established between the responses of different people being interviewed. If convergence is not established through the interview process, then an observation method will need to be used.

Observation as an initial data collection method would be cumbersome since it would take a significant amount of time to observe enough interactions to come to a conclusion. Therefore, it does not meet the objective for minimizing researcher effort. It also does not have much flexibility since the researcher cannot specifically ask for a particular interaction to happen. The researcher has to wait and see if a data collection worthy action occurs. However, if the observation is guided by information obtained from interviews, it becomes another viable method to establish convergence and therefore validate the data collected. Therefore, the overall framework begins with document analysis, proceeds to interviews, and finally ends with observation if necessary. Figure 3.2 illustrates the framework. With the overall framework developed, a protocol for each methodology is needed to provide a standardized process for 
applying each methodology. This is important to allow the framework to be used by other researchers in the future. 


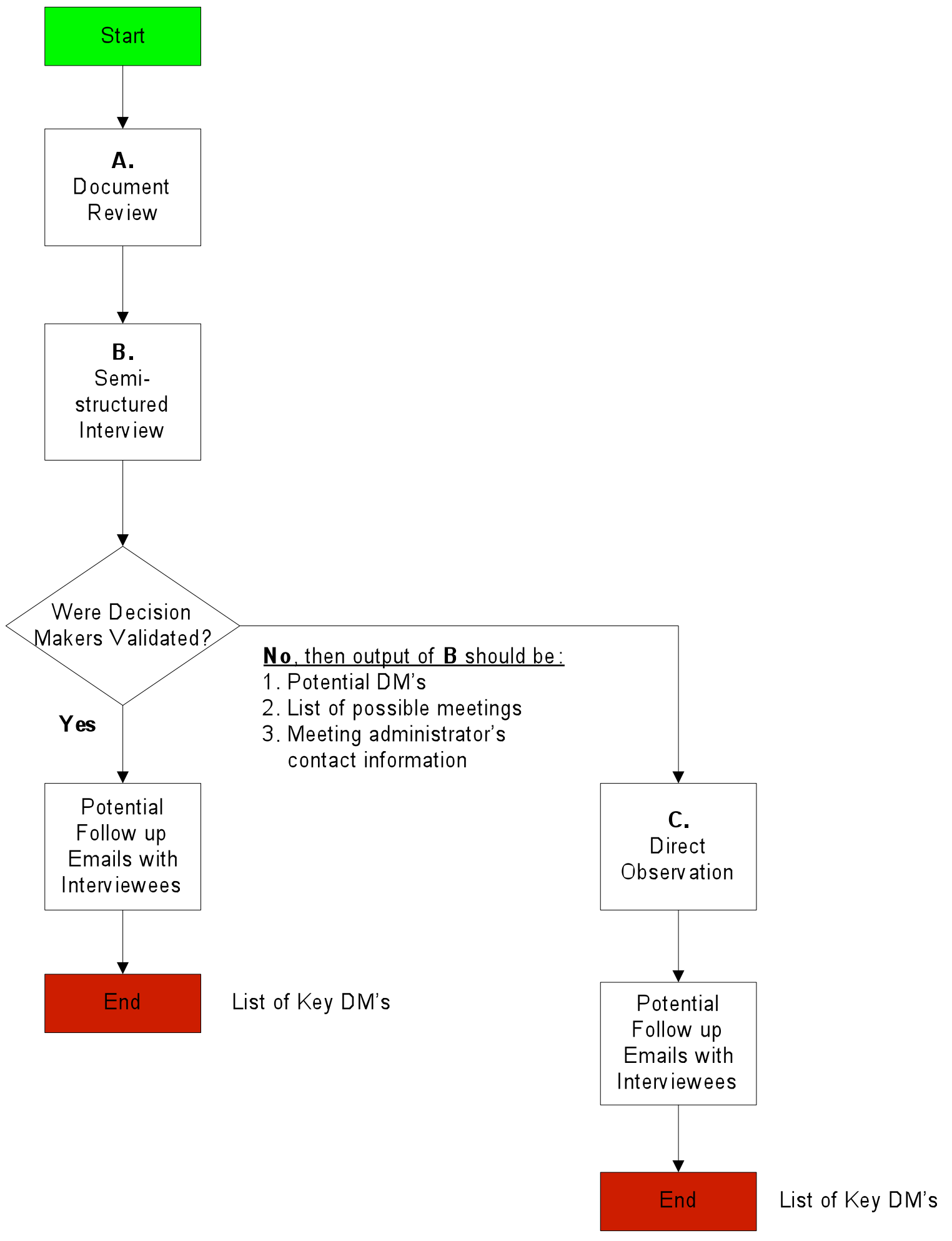

Figure 3.2: Framework for Identifying Key Decision Makers (DMs) 


\subsection{Protocol Development}

Each protocol follows the same basic structure. They begin with a heading section that lists any inputs from the other protocols, the potential outputs of the protocol being looked at, and any items needed to execute the protocol such as Institutional Review Board (IRB) approval. This was done to make it easier for other researchers using the framework to be able to quickly identify what the major components of the protocol were as well as making it easier to understand how the data flows between protocols. The next section is an introduction that gives the overview of the objectives of the protocol, and its general purpose so other researchers can understand what the protocol should accomplish. From there, each protocol goes down the list of potential outputs that are identified in the heading section and fully develops how to pursue obtaining each potential output. Finally, the end of each protocol may have appendices that include charts, definitions, or some other piece to help facilitate obtaining the outputs of the protocol. Figure 3.3 is an example of the general protocol structure. 


\section{Protocol Example}

Other Data Instrument Inputs

1) List of inputs from other protocols in the framework

Potenti aDutputs

1) List of potenti al protocol outputs

Items Needed to Execute

1) For example, IRB approval

Introducti on

Describes the general objecti ves andpurpose of the protocol

Specifi c Protocol Procedure

This is where the specifi c protocol procedure is defi ned.

Appendices (if applicable)

Any appendices like charts, fi gures, or related material appear here.

Figure 3.3: Protocol Example

With the basic structure of the protocols laid out, each protocol can be described in greater detail in the following sections.

\subsubsection{Document Review Protocol}

The document review protocol begins the framework and is primarily responsible for providing a starting point or point of contact for the interview protocol. If an owner has and gives a researcher access to all of its programming, construction, and turnover documentation, it is possible for the document review protocol to identify key decision makers but not necessarily 
validate them. As mentioned earlier, some the documents that this protocol seeks to find are organizational charts, turnover documentation, project documentation, and similar documents that indicate someone making a decision or having made a decision about a building system. These documents could be classified into two broad categories. The first is normative documents that describe how the process should work, and the second is descriptive documents that record what actually occurred. Unfortunately due to the possible variability in documentation that owners retain and the potential variability of the quality of those documents, the document review protocol had to be very flexible. While this is not necessarily a problem, it did result in less specificity in the protocol itself. A general direction was provided but not a lot of specific instructions. The document review protocol has no informational inputs but has several potential outputs. The outputs include a list of potential decision makers, a list of candidate projects, and a list of possible construction meetings with some contact information for those meetings (See Appendix B).

To aid in searching for documents to identify potential decision makers, the protocol included examples of phrases or language that might provide clues to who were the important actors in a given project. For instance, the phrase, “...person $\mathrm{x}$ is solely responsible for approving system $\mathrm{y} . . . "$, if found in a document, would clearly indicate the role of key decision maker relative to that system ${ }^{1}$. Another potential clue would be an approval stamp or an "approved by" box with a signature. Since relationships between people are difficult to capture from documents, the verbiage has to be very specific to say with some level of certainty that someone is a key decision maker. In the case of less specific language being used, the researcher can use it as a clue to look elsewhere or as a specific point of inquiry for an interview. Since one of the characteristics of an institutional owner is a standardized procurement procedure, the documents may only list a role or position instead of an actual person. For example, instead of giving the name of the person responsible for paint color decisions, a document may say the interior designer is responsible for paint color decisions. For this research, the difference between a role and an individual does not affect the outcome because both instances refer to a

\footnotetext{
${ }^{1}$ It is worth noting that these phrases are examples and judgment will need to be exercised by future researchers
} 
single entity.

Since one of the objectives of the document review protocol is to feed the interview protocol with necessary information, a list of candidate projects is necessary to give the interview a project to focus on. To obtain a list of candidate projects, a researcher needs to go to the organization's website and search for key words found in the protocol. If the owner does not have a website, the researcher will have to rely on documents that can be obtained from the owner directly. According to the characteristics of Institutional owners, they typically have several projects at different stages of a project's lifecycle and with different general building characteristics. Therefore, to help the researcher select which projects to focus on during the interview process, the researcher should create a chart of the different projects with some of their basic characteristics. This chart will help the researcher by graphically representing the distribution of characteristics among the projects. It is important to have a sample of buildings with similar characteristics to reduce the number of potential sources for error. Figure 3.4 is an example of what a chart could look like. The characteristics considered in the example are the project delivery method, stage in the construction process, the gross square footage (GSF), and an indication of if the building is a laboratory building or not. Since Virginia Tech is the subject of this research, these characteristics were chosen to get a feel for the general size of the project and to distinguish between buildings with very different design requirements. For example, a classroom or office building has very different design requirements than a chemistry lab building. The differences in design requirement could result in significant impacts on who makes decisions about the building characteristics. The building characteristics in questions could be changed to fit whatever future researchers feel is important. The general characteristics of the organization that a researcher is investigating will help determine the important characteristics to capture for this chart. 


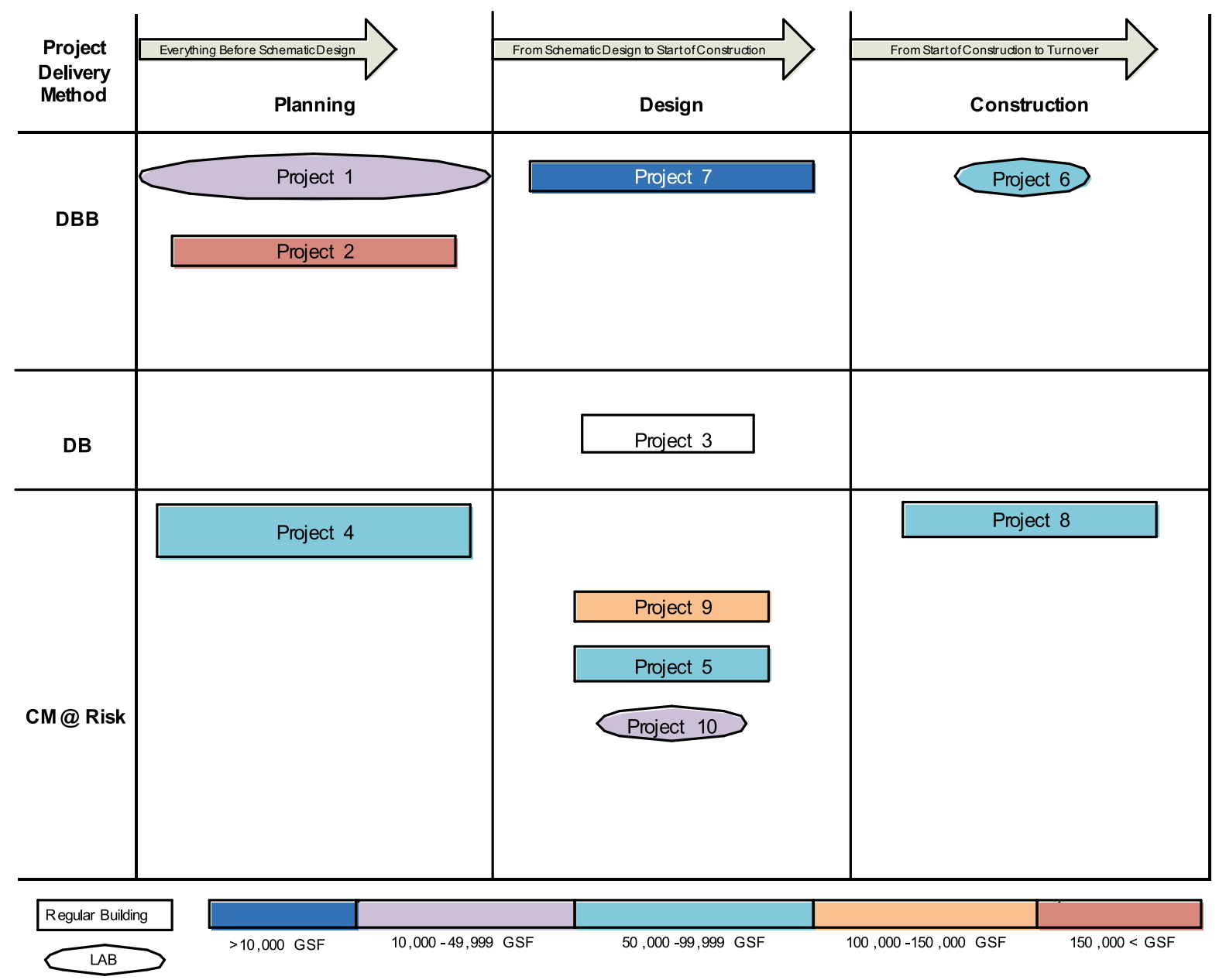

Figure 3.4: Candidate Project Map

A list of as many project participants as the researcher can find for each project should accompany this chart so the researcher will several options to choose from to start conducting interviews. Of the project participants, the project manager (PM) is the preferred point of contact since the PM is exposed to the greatest number of potential key decision makers by the very nature of the position.

Since subsequent protocols may require the researcher to attend project meetings, the researcher should also look for documents that list the meeting requirements of the institutional owner. Searching for terms such as "construction project meetings" or "project meetings" should yield the required documents and potentially yield the meeting administrator contact information. It is important to determine who the meeting administrator is in order to 
obtain permission to come to the meeting. The list of meetings may not be complete and may not specify meetings for a single project since each project is unique, but there should be at least one document describing the meetings a typical project should have since by the definition of institutional owner, there should be some documentation for standardized procurement. From there, the details for which meetings to attend can be determined during the interview process.

\subsubsection{Semi Structured Interview Protocol}

The semi structured interviews are the main vehicle for data collection. The document review provides the background information and starting points necessary for the interview protocol to be effective. The primary objectives of the interview protocol are to validate the findings of the document review protocol if the protocol found key decision makers, or to determine who the key decision makers might be if none were found in the document review. A secondary objective is to determine construction meetings to attend and the associated meeting administrator's contact information (See Appendix C).

The main reason for using a semi structured interview was to allow the researcher the flexibility to change tactics or questions as the interview progressed. A structured approach would have made the data easier to manipulate due to the standardization of the questions, but this would have not allowed the researcher to explore the responses of the interviewee. It also would have prevented the researcher from being able to qualify the questions being asked if the interviewee was confused about them. Without the ability to guide the interview and qualify the questions as necessary, the researcher would have had to rely on the interpretation of the interviewee. This could have led several responses to be useless to the researcher. The flexibility of the semi structured approach turned out to be very useful for the researcher and will be discussed further in subsequent chapters. This flexibility does put unique demands on the researcher. The researcher will need to thoroughly understand the culture and have mastery of language of the people being interviewed. If these qualities are not present in the researcher, it will potentially cause the researcher to miss important information concerning who the key decision makers are. For example, someone who doesn't have mastery of the 
language may not pick up on a comment made "under the breath" of the interviewee. Therefore, only researcher with a thorough understanding of the culture and mastery of the language should use this protocol.

The interview starts with a description of the project and the establishment of key concepts/definitions. They are as follows:

1) Key decision maker - The person or group who has the most influence on the system. If it is a group, the group must act like a single entity.

2) Rubber stamp decision maker - A superior who simply signs off on any request of his subordinates without detailed review or contributing to the analysis.

The next step of the interview was to show the interviewee the High System Cost Chart (HSCC) and ask them if they felt that the systems on the HSCC were, in their opinion, accurate from a lifecycle cost perspective. This was an important step because the US Department of Commerce study that the HSCC is based on only considered system costs up to total installed cost. It did not try to extrapolate a lifecycle cost. While it would still be important to determine who the decision makers are for systems with the highest total installed cost, it is more advantageous to consider systems from a lifecycle perspective. This allows sustainable technologies to be given fair consideration since they typically have slightly higher initial costs but save over the lifecycle. With the foundation for the interview laid through the key definitions and the HSCC, the interview could move forward and begin probing for key decision makers.

The interview protocol probed for key decision makers through an identification and elimination process. The interviewee was asked to list all the decision makers they felt were "key" according to the established definition for each building system in the HSCC. With the list of decision makers completed, the interviewee then had to choose the top one or two most influential decision makers from the list for each system. These decision makers were then considered to be the "key" decision makers for the project, subject to validation as discussed previously. This step could provide both initial identification and validation at the same time if three of more of the interviewee's identify the same key decision maker. 
The last step for the interview protocol was to ask if the interviewee knew of any upcoming project meetings that the researcher could attend, and ask for the contact information for the meeting administrator. This last step may or may not be necessary depending on how convergent the interview responses are.

\subsubsection{Indirect Observation Protocol}

The indirect observation protocol is only used for validating the findings of the previous two protocols by provide enough information to triangulate the data (See Appendix D). The protocol starts by obtaining permission for the researcher to attend the meeting since it would be very inappropriate for a researcher to show up at a meeting unannounced. Once at the meeting, the researcher's first step is to identify all the people who will be present at the meeting. Ideally, this will be done before the meeting begins so the researcher can the focus on the content of the meeting itself. If there are people at the meeting that were not identified before the meeting, the researcher can either approach them directly or ask the meeting administrator to identify them after the meeting. While the meeting is in progress, the researcher must listen for

phrases such as "I will be responsible for ____, "You take the lead with item___, or similar phrases where someone is indicated to make decisions concerning one of the building systems of interest. If the verbiage similar to this is used, this person should be identified as a potential key decision maker. By combining this data with data collected previously, the findings should be validated. If they are not, the researcher will need to go back and conduct more interviews and potentially attend more meetings to collect enough data to validate the findings. 


\section{Chapter 4: Data Collection and Analysis}

This chapter reports the findings and experiences of the researcher from testing the framework, and its applicable protocols. The organization to which the researcher applied this framework to was Virginia Polytechnic Institute and State University or simply Virginia Tech (VT). Virginia Tech meets all of the characteristics for an institutional owner. Its assets are not readily traded, it has facility procurement standards, has an in-house construction department, has several concurrent capital projects, has projects at different stages of development, and assets have a design life greater than 50 years.

\subsection{Document Review Findings}

The researcher began the document review protocol by looking on Virginia Tech's website for a link to their construction or facility department's website. Construction at Virginia Tech is administered by the Virginia Tech Facilities Department. The Facilities Department did have a website which is where the researcher conducted most of the document review. In addition to looking on the website, the researcher tried to look at actual project files. Unfortunately after seeking access to the project files through a cooperative member of the Facilities Department, the researcher was essentially told that access to the project files would not be given. However, the researcher was able to find enough information to successfully seed the semi-structured interview protocol.

\subsubsection{Decision Maker Investigation}

The document review protocol lists several different documents to specifically look for while looking for actual decision makers. The researcher began attempting to find the documents on that list. The documents to start with are as follows:

1) Organization charts or similar roles and responsibility charts

2) Standard operating procedures, especially construction related procedures

3) Annual reports

4) Historical project files 
The researcher was able to find the organizational chart for the facilities department as well as for the Office of the University Architect (OUA). Figure 4.1 is the facility department's organization chart; however, it only goes down to the director level. By looking at the personnel list on the facilities website, the researcher made the determination that the organizational chart did not have enough granularity to identify decision makers because there were several more people listed on the website but not on the organizational chart. The OUA organizational chart did have more granularity; therefore, the researcher did consider the people on it to be potential decision makers. However, the position descriptions were not specific enough to determine if any of them were key decision makers for this research.

\section{FACILITIES SERVICES}

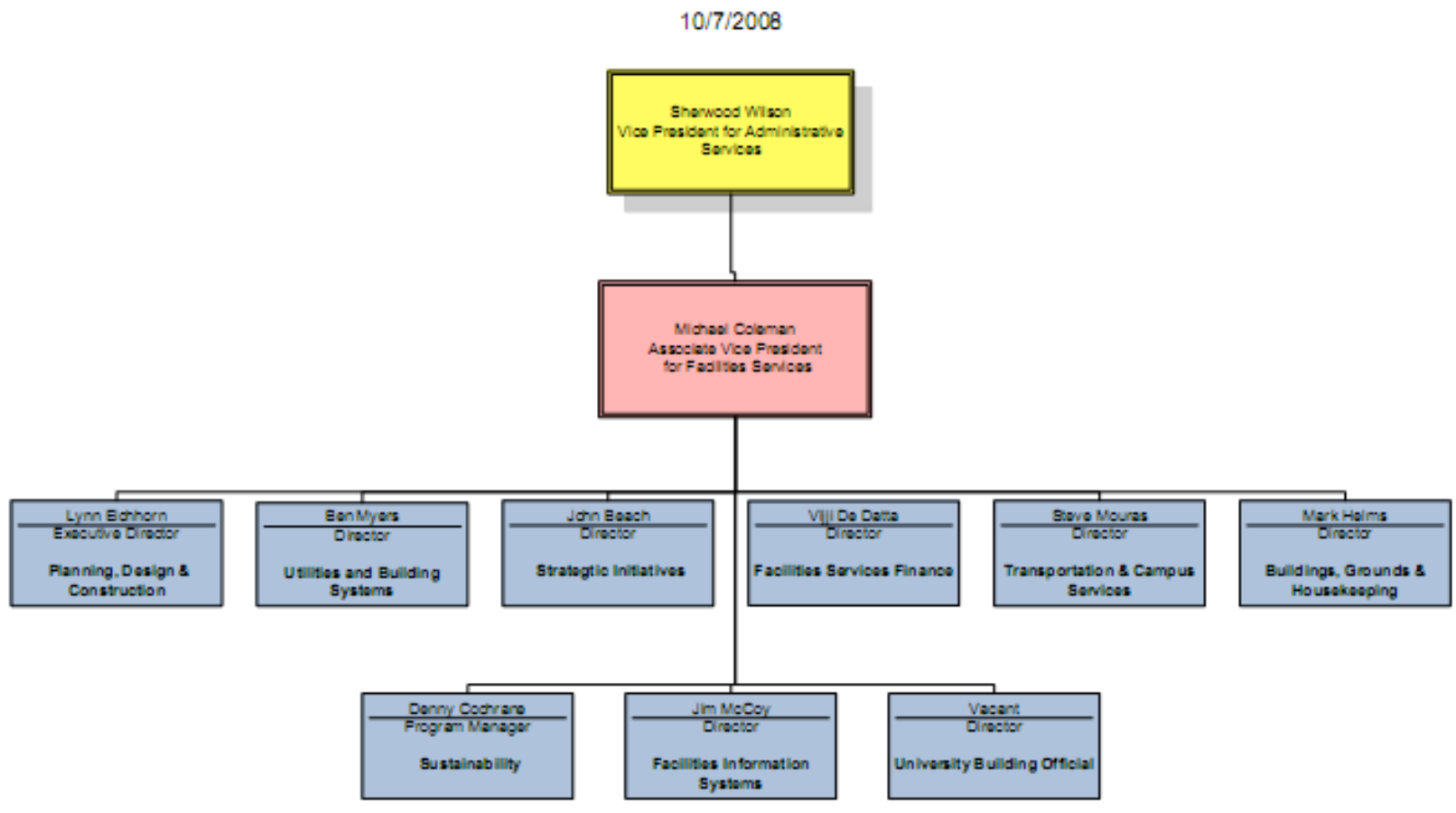

Figure 4.1: Facilities Organization Chart (Virginia Tech 2008)

The next set of documents the researcher tried to find were standard operating procedures. Some of the documents the researcher was able to find were as follows:

1) Design and Construction Standards

2) Design Standards for Learning Environments 


\section{3) Construction \& Professional Services Manual (CPSM)}

The Design and Construction Standards did not identify any decision makers because it focused on general guidelines such as numbering styles, door sizes and finishes, or similar guidelines. It did not specify either people or offices responsible for meeting these guidelines. The same was true for the Design Standards for Learning Environments. The CPSM has a lot of information concerning standards for roof construction, other material standards, and the overall flow of a project, but it also did not yield any decision maters. The problem with the CPSM is that it is for the entire state of Virginia, not just VT. As a result, it was not specific enough to identify decision makers.

With that avenue explored, the researcher went on to look at annual reports. The researcher was able to find annual reports for 2004, 2005, and 2006. Upon reviewing these documents, the researcher determined that decision makers would not be identified through them either because they are very general in nature. The annual reports simply hit the highlights of that particular year by conveying information like the amount of money spent that year, any buildings that had been completed, or the status of any real large projects. This left historical project files as the last set of documentation to look into.

The researcher went to the Facilities Department to try and look at historic project files; however, the document review protocol did not include instructions for how to look for historic documents. Fortunately, while looking for construction standards, the researcher had found a document listing the types of documents that are kept by Facilities; therefore, the researcher had a starting point. The document review protocol was then modified to include some guidance for finding historical documents. The document requirements for Facilities are in Table 4.1. Unfortunately, when the researcher tried to obtain these documents, the Facilities Department could not allow access to them. The researcher asked one of the project managers for access, but the project manager was not able to grant the access because all of the project files are stored in an electronic database. Virginia Tech does not keep paper files on hand. Once a project is finished, VT sends any paper files to long term storage. With the decision maker section completed, the researcher went on to find candidate projects to investigate further. 
Table 4.1: Required Documents (Virginia Tech 2009)

\begin{tabular}{|c|c|c|c|c|}
\hline$\vec{\square}$ & Construction Plans \& Specs & Qty & Notes & Due Date \\
\hline & Paper & 1 set & & \multirow{2}{*}{$\begin{array}{c}\text { Prior to } \\
\text { Occupancy }\end{array}$} \\
\hline & & & & \\
\hline$\vec{\nabla}$ & O \& M's \& Warranties & Qty & Notes & Due Date \\
\hline & Paper & 1 set & & \multirow{2}{*}{$\begin{array}{c}\text { Prior to } \\
\text { Occupancy }\end{array}$} \\
\hline & PDF & 1 set & Bookmark Sections & \\
\hline$\vec{\Delta}$ & Construction Submittals & Qty & Notes & Due Date \\
\hline & Paper & 1 set & & \multirow{2}{*}{$\begin{array}{c}\text { Prior to } \\
\text { Occupancy }\end{array}$} \\
\hline & PDF & 1 set & Bookmark Sections & \\
\hline$\vec{\nabla}$ & Drawings & Qty & Notes & Due Date \\
\hline & Paper & 2 sets & & \multirow{3}{*}{$\begin{array}{c}\text { Within } 60 \text { days } \\
\text { from date of } \\
\text { Occupancy }\end{array}$} \\
\hline & CAD & 1 set & Must meet VT CAD Standards & \\
\hline & PDF & 1 set & & \\
\hline$\vec{R}$ & Specs & Qty & Notes & Due Date \\
\hline & Paper & 1 set & & \multirow{2}{*}{$\begin{array}{c}\text { Within } 60 \text { days } \\
\text { from date of } \\
\text { Occupancy }\end{array}$} \\
\hline & PDF & 1 set & Bookmark Sections & \\
\hline
\end{tabular}

\subsubsection{Candidate Project Identification and Selection}

In order to seed the semi-structured interviews, the researcher needed to find out what projects were currently being pursued at Virginia Tech. By the definition for institutional owner put forth by the researcher, an institutional owner should have several capital projects ongoing. Virginia Tech certainly met this requirement of the definition because the Facilities Department had a link to a new construction wiki and to a construction report. The new construction wiki only had projects currently being constructed on it, but the construction report had a list of all projects in planning, design, and construction. The construction report listed 36 different projects at different stages of development. In order to attempt to triangulate results, at least 3 projects needed to be selected to be investigated further. Picking 3 projects from a list of 36 is difficult since each project has different characteristics. As a result, the researcher created a chart of all the different projects to aid in the selection of the sample to investigate using the interview protocol.

Any potential researcher who will use this framework will have a unique set of circumstances that are driving the research. Therefore, it is difficult to set a hard and fast method for creating 
a project chart. Each researcher will need to determine which building attributes are the most significant for the research and classify the buildings according to them. For the research at VT, the project delivery method, the size of the building, the stage of development, and the building type were the most important building characteristics for reasons mentioned previously. Figure 3.4 shows an example of the project map the researcher created. Appendix G contains the actual project map with all the buildings on it. The Institute for Critical Technology and Applied Science (ICTAS) buildings I and II and the Engineering Signature Building were selected for further investigation. These were selected for the following reasons:

1) One of them fell in each project development phase

2) The ICTAS buildings were both mixed laboratory and office space type buildings

3) The Engineering Signature Building was the largest facility in the construction report

4) All of them were different sizes.

Once these projects were selected, the researcher looked up the projects on the construction wiki to find the project managers. The researcher was only able to find the project manager for ICTAS I. The other two projects were still in planning or design and had not made it far enough in the process to be put on the wiki yet. The researcher decided he would start with interviewing the ICTAS I project manager and find out who the other project managers were during the interview. With the candidate projects found and the projects for further investigation identified, the researcher went on to try and find possible meetings to attend for these projects.

\subsubsection{Possible Meetings Identification}

The researcher needed to find potential meetings to attend in case they were necessary to validate the findings of the research. The researcher searched the Facilities and Virginia Tech websites for the key terms listed in the document review protocol, but meetings for each of the identified projects were not to be found. The researcher was able to find a list of meetings that any project at Virginia Tech was supposed to have. The researcher exercised judgment and determined that this was sufficient since actual meetings to attend could be identified during the interview process. Since the meetings found were generic in nature, it was impossible for 
the researcher to determine who the meeting administrator was. As a result, this part of the document protocol was not pursued.

At the end of the document review protocol, the researcher had not found any decision makers, but several projects were identified for further investigation. In addition, at least one project participant was identified, and a list of standard meetings was discovered. Next, semistructured interviews were to be conducted.

\subsection{Semi-Structured Interview Findings}

The first interview to conduct was the project manager for ICTAS I. He was the only project manager the researcher was able to identify since the other buildings to be investigated were not far enough along in the development process to be listed on the Virginia Tech or Facilities website. The researcher emailed the project manager for the ICTAS I project and set up an interview appointment.

\subsubsection{First Interview}

The researcher began the interview with the ICTAS I project manager by thanking him for his time and having him sign the release forms needed by the Institutional Review Board (IRB). From there, the researcher started by summarizing the overall objectives of the research and painting a "big picture" view of the research. With the overall description completed, the researcher pulled out a copy of the High System Cost Chart (HSCC) and showed it to the project manager. As the researcher was explaining how the HSCC was created, he saw an opportunity to improve the interview protocol by asking the project manager if he agreed with the systems on the HSCC from an operations and maintenance (O\&M) standpoint. This was important because the study the HSCC was based on only considered total installed cost. While this fact is not necessarily a problem for everyone else who might use this framework, the researcher was interested in identifying decision makers who had the greatest impact on TCO. Therefore, in an effort to validate the HSCC from a TCO perspective, the researcher added a question asking the project manager to give their opinion on if the systems on the HSCC were representative of the most expensive systems from a TCO perspective. For this interview, the project manager felt that the superstructure system would not be an issue from a TCO standpoint, but that plumbing 
and roof maintenance would be. The researcher then went on to defining some key terms and concepts such as what a key decision maker was and the difference between a decision maker and a rubber stamp decision maker. With foundation laid for the interview, the researcher proceeded to identify decision makers.

The researcher asked the project manager to list all the key decision makers that he could think of for each of the systems on the HSCC. It was during this process that another change to the interview protocol was identified. The project manager did not know if the different building codes and Virginia Tech's own internal code was a given or not. If not, who wrote them would be a very significant decision maker. Since building codes are essentially law, the researcher told the project manager to consider any codes or similar requirements as a constant for the research. With that issue cleared up, the project manager was able to list who he felt the key decision makers were. By the time the project manager finished, the interview had taken longer than the researcher had anticipated. In an effort to streamline the interview, instead of having the project manager rate each decision maker he identified according to how important they were, the researcher simply had the project manager circle the one or two most important decision makers for each system. These people or groups were considered the true key decision makers for the project. The results of the interviews can be found in Table 4.2. To bring the interview to a close, the researcher asked for the names of the project managers for the other two projects under consideration. The ICTAS I project manager actually took the researcher to the offices of the other two project managers and introduced him. The researcher then scheduled interviews with both of them. 
Table 4.2: Interview Results

\section{Preliminary Decision Maker Data (Most Infl uencial Group Highlighted)}

\begin{tabular}{|c|c|c|c|c|}
\hline System & Project Manager 1 (ICTASI) & Project Manager 2 (Engineering Sig.) & Project Manager 3 (ICTASII) & User/Owner (ICTASI) \\
\hline \multirow{8}{*}{ Exterior Enclosure } & Board of Visitors (BOV) & BOV & OUA & BOV \\
\hline & Offi ce of the Universti y Architect (OUA) & OUA & Amanda & OUA \\
\hline & Art \& Architecture Review Bo ard (AARB) & AARB & ICTAS Staff & ICTAS Staff (medallion design) \\
\hline & Physical Plant & VP of Faciliti es & & Julie \\
\hline & Project Manager & Amanda & & $\mathrm{AE}$ \\
\hline & Suzzie & $A E$ & & $\mathrm{BCOM}$ \\
\hline & VP of Faciliti es & & & \\
\hline & $A E$ & & & \\
\hline \multirow{6}{*}{ HVAC } & Mechanical Designer & Physical Plant - Mechanical Services & Physical Plant - Mechanical Services & Physical Plant \\
\hline & Physical Plant & $A E$ & Senior Mechanical Eng. & \\
\hline & Project Manager & BCOM (only forfi re and safety) & & \\
\hline & VT Uti liti es & VP of Faciliti es & & \\
\hline & $\mathrm{AE}$ & & & \\
\hline & VT Commissioning & & & \\
\hline \multirow{3}{*}{ Electrical } & Electric Service & Dan & Dan (Inside Building) & Dan \\
\hline & Dan & BCOM & Jo seph (Outside Building) & \\
\hline & $A E$ & & & \\
\hline \multirow{3}{*}{ Superstructure } & ICTAS staff (program requirements) & Budget & Structural Engineer & Structural Engineer \\
\hline & Structural Engineer & Structural Engineer & & ICTAS Staff \\
\hline & & BCOM & & Commissioning Agent \\
\hline \multirow{4}{*}{ Interior Finishes } & OUA - John & College of Engineering (User) & John & ICTAS Staff \\
\hline & Head of Housekeeping & $A E$ & ICTAS Staff & John \\
\hline & $\mathrm{AE}$ & & Amanda & Bill \\
\hline & & & $A E$ & $A E$ \\
\hline \multirow{2}{*}{ Conveyance } & Dan & Dan & Dan & Dan \\
\hline & ICTAS Staff & $\mathrm{BCOM}$ & & \\
\hline
\end{tabular}


With the first interview completed, the researcher realized that it would be best to record future interviews if the interviewee agreed to being recorded. The researcher had found it difficult to take notes on the interview while also guiding the interview and answering questions. Recording the interviews also allowed the researcher to go back after the fact and perform more analysis if necessary. The researcher then set about making the changes to the interview protocol and went back a couple days later to the Facilities Department to conduct the interviews of the other two project managers.

\subsubsection{Second and Third Interviews}

The second and third interviews both followed the same structure as the first one, but incorporated the previously stated changes. The second interviewee did not agree to being recorded, but the third interviewee did. A transcript of the interview with the third interviewee is in Appendix F. When the researcher asked about their opinions on the HSCC from a TCO perspective, the second interviewee indicated that he was not involved in O\&M, but that it looked fine to him. The third interviewee agreed with the HSCC, and also said that the electrical system was the most expensive. Both of them had no problem understanding the definitions or the distinction between a normal decision maker and a rubber stamp type. The listing of the decision makers for each system also went much smoother than it had during the first interview. Therefore, the researcher did not feel the need to further modify the interview protocol. The results of these interviews are also found in Table 4.2.

The three people interviewed to so far were all project managers, but to further validate the findings, it was necessary to interview at least one person outside of the Facilities Department. Therefore, the researcher asked the project manager of the ICTAS I building for the contact information for the building manager of ICTAS I. The building manager was involved in the development and construction of the building because it is the building manager's responsibility to represent the needs and concerns of the ICTAS I staff. The ICTAS I project manager gave the researcher the contact information, and the researcher then set up an interview with the building manager. 


\subsubsection{Fourth Interview}

The fourth interview was of the ICTAS I building manager. During the interview, the researcher found out that the building manager for ICTAS I was also the building manager for ICTAS II. The researcher had the option to have the building manager identify key decision makers for both buildings but decided not to because it might bias the interview results.

The building manager agreed to being recorded, and the transcript of the interview is in Appendix $E$. The researcher was surprised at how quickly the building manager understood the HSCC and the distinctions of key decision makers. As a result, the interview quickly progressed to identifying decision makers. It was interesting that the building manager spent more time and seemed to have a more detailed understanding of the players involved in the exterior cladding and interior finishes systems. The project managers had spent more time talking about issues like the roofing system or the HVAC system. The building manager provided a lot more detail of how the occupants of the building interacted with the building. Even though these sorts of details were not directly related to the objectives of the interview protocol, the researcher recorded the information to get a better understanding of how the users fit into the development of capital projects of institutional owners. The responses of the building manager are shown in Table 4.2.

With the interviews completed, the next step of the framework is the indirect observation protocol.

\subsection{Indirect Observation Findings}

There was a sufficient amount of convergence in the responses of the four interviewees to justify not pursuing the observation protocol. The significance of the convergence is discussed more in the next chapter. 


\section{Chapter 5: Validation}

This chapter discusses the validation efforts for this research. First the document review protocol validation methods are to be discussed, and then the semi-structured interview protocol will be discussed. The indirect observation protocol was not used; therefore, it was not validated.

\subsection{Document Review Protocol Validation}

To validate the document review protocol, the researcher employed an inter-rater reliability method by asking two other people to go through the protocol and see if their findings matched those of the researcher. The first rater was a PhD student and had no knowledge of the purpose of the research or what key decision makers were and why they were important. The second rater was a sophomore and had a limited understanding of the research and what decision makers were.

The first rater was not able to identify any potential decision makers, but the researcher had not found any either so there was no significant discrepancy there. Significant discrepancy was only evident for the remaining portions of the document protocol. The rater did not find any of the organizational charts that the researcher had. The rater only found three buildings that had been built recently as candidate projects. The rater did not create a chart of the projects even though the protocol directed the rater to do create one. The rater also did not find any potential meetings to attend or the contact information for the meeting administrators. Even though the researcher had not been able to find that information either, the researcher had found documentation of standard meetings for all projects that the rater did not find.

The second rater did find the organizational chart for the Facilities Department but did not find the organizational chart for OUA. The second rater was also not able to find any clear decision makers either. The second rater was able to find the same list of projects that the researcher had found and also created a chart of the projects according to the protocol. For possible meetings and meeting administrator contact information, the rater found some minutes for different meetings and extracted meetings and some contact information from them. 
The first rater seemed to have a significant amount of trouble executing the protocol. One possible explanation is that this was due partly to lack of vested interest on the part of the rater because it took the rater about a month to get the results back to the researcher. The researcher also could not determine a reason for not creating the project map since it was clearly indicated in the protocol.

The second rater seemed to understand the protocol relatively well since he was able to give the results to the researcher within one working day. While the second rater did not find all the organizational charts that the researcher did, the researcher decided that it was a reasonable difference since the rater did not have as much background knowledge or personal interest in the project. The only area of apparent confusion on the part of the rater was the documents the rater found for identifying potential meetings and contact information. Of the documents found, only two of them had to do with individual building projects. The remaining three were minutes from different university committees. The minutes from the building projects did identify one meeting and the contact information for the meeting administrator, but the particular meetings had already happened and future meetings were not identified in the minutes. The rater also had not found the same document listing the standard meetings for projects at Virginia Tech. Upon reviewing the results from the second rater, the researcher determined that the document review protocol needed to be modified to be more specific about what the qualifications for potential meetings should be.

In summary, the first rater did not validate the findings of the researcher, but since the first rater was able to find at least three projects with contacts for each one, the framework still could have advanced to the interview phase. The second rater found many of the same things that the researcher had. One possible explanation for the differences can reasonably be the greater knowledge of the area and the greater interest in the results on the part of the researcher. An important limitation for this research is that any future researcher who would use this framework would need a similar level of knowledge and interest to achieve a similar correlation in findings. 


\subsection{Semi-Structured Interview Protocol Validation}

To validate the findings of the interview protocol, the researcher utilized the triangulation approach previously mentioned. The researcher recorded the responses of the different interviewees and looked for convergence in their responses. There was an unexpectedly high convergence rate among the interview subjects. Of the six systems on the HSCC, all four interviewees identified the same key decision maker for three of them. Three of the four interviewees identified the same key decision maker for two of the other systems, and the system with the least convergence had only two interviewees identify the same key decision maker. Table 4.2 summarizes the findings of the interviews.

Since three or more of the interview subjects had the same response for all but one system, the interview responses successfully identified key decision makers for the systems on the HSCC. Also since the building manager's responses were remarkably convergent with the project manager's response, more credibility can be given to the validity of the data. Due to the convergence found at this stage in the framework, it was not necessary to employ the indirect observation protocol. 


\section{Chapter 6: Conclusions}

The chapter summarizes the conclusions that were drawn from this research.

\subsection{Research Conclusions}

This research set out to answer the question of who are the key decision makers that impact a facility's TCO, and what framework should be used to identify them? The first half of the question was answered through the development of the HSCC. The key decision makers that impact a facility's TCO are the key decision makers for the six systems found on the HSCC. The second half of the research question required more analysis.

\subsection{Order of Protocols}

The development of a framework to identify key decision was based on work done by Grossi who conducted research on stakeholder analysis. The order of employing the methodologies was an important aspect of the framework because each one has its own strengths and weaknesses that should be utilized to achieve the best overall result. The protocols for each methodology form the backbones of the framework. It is the testing and validating of these protocols that were critical to the successful development of the framework.

\subsection{Validation of Protocols}

Validating the document review protocol was the most difficult because getting suitable people for inter-relater reliability testing proved to be challenging. Neither of the raters had a comparable knowledge base as the researcher in the objectives of the framework or the field of identifying stakeholders. Another challenge was getting the same level of effort from the raters as the researcher. This proved to be very difficult with one of the raters. Even with these challenges, the document review protocol accomplished its purpose because it did provide enough information for the interview protocol to begin.

The interview protocol was much easier to validate because triangulation and convergence of response was the primary validation indicator. The convergence level really surprised the researcher. The researcher did not anticipate that four different people without communicating 
would have such a level of convergence. For the one case that this framework was validated as a tool for, the findings suggest that there is a high level of standardization and definition of roles across the institution.

The indirect observation protocol was not tested because of the interviews had enough convergence to achieve validation. It is still an important measure to consider for future applications of the framework to give researchers one more avenue to validate who the key decision makers are. If after using that the indirect observation protocol key decision makers are not identified, then the researcher might have to consider starting the framework again or revisiting some of the protocols to make sure no information was missed.

\subsection{Research Summary}

In summary, the framework was validated as a tool for identifying key decision makers for the institution studied. The findings of applying the framework to this test case suggest that its application to other institutional owners may be useful in identifying key decision makers for capital projects in other contexts. 


\section{Chapter 7: Discussion}

This chapter provides the researcher with a platform for noting several of the intriguing observations made throughout the course of this work.

\subsection{Document Types}

Throughout the course of this research, the researcher observed several interesting actions, events, and outcomes. From the initial development of the framework, the researcher noticed that the types of documents could be sorted into two broad categories. The first type is normative documents where the document prescribes how a process or action should be done. For instance, procurement standards are normative in nature. The second is descriptive documents that describe how a process or action was executed. An example of a descriptive document is a Request For Information (RFI) or a project memo. From the observation of these two categories, the researcher considered whether or not it could be possible to identify and validate the key decision makers from documents alone. Typically, using a single research method does not provide sufficiently unique data for both initial collection and validation to occur. However, given the two different types of documents, it might have been possible to accomplish this using triangulation within both categories. For example, if at least three different normative documents identified a particular decision maker and then three descriptive documents identified the same decision maker, one could make the case that the findings were validated. This would only be possible if the researcher was given access to both types of documents. Ultimately, the researcher chose not to include this in the development of the framework in order to give the framework greater credibility.

\subsection{People as Data}

Another observation that the researcher made was the difficulty of treating people as data instead of human beings. This was primarily a struggle when reporting the results of the interview protocol. It was easy to remember to keep the names of the people interviewed confidential, but keeping the names of people that the interviewees mention confidential was surprisingly difficult. Future researchers should replace any names mentioned in the interview 
with either a number or some other generic representation as soon as the interview is concluded.

The decision to record the interviews brought some interesting thoughts for consideration. The decision to record the interviews was made because the researcher found it too difficult to answer the interviewee's questions, guide the interview, and take detailed notes simultaneously. In order to record the interviews, the researcher had to revise the IRB protocol by creating special permission statements for the interview subjects to sign to obtain IRB approval. The researcher initially felt that there would be no objections to having the interview recorded, but the first subject that was interviewed refused to be recorded. This caused the researcher to wonder about what sort of affect the recording of the interviews was having on the responses of the interviewees. Were the interviewees responding with more normative answers, or were they comfortable enough to respond as they truly perceived the project? Were they "toeing the party line" or not? The researcher does not believe that this was the case with this research because the responses of the interviewee who refused recording was the same as those who were recorded. Also, the interviewees who were recorded did not indicate any uneasiness with being recorded. The researcher tried to mitigate any affect the recording might have by placing the recording device out of the line of sight of the interviewee in the hope that the interviewee would forget that they were being recorded. None the less, it is an interesting issue that might warrant further consideration by future researchers.

\subsection{Stakeholder Theory}

The final area of interest is the possible further application of stakeholder theory to the findings of the framework. Mitchell et al. (1997) proposed three characteristics for defining the salience of a stakeholder. They are power, legitimacy, and urgency. Each of these characteristics is at different levels within each stakeholder, and all three need to be at a certain level in order for a stakeholder to have enough salience to accomplish an action. As the key decision makers were identified, the researcher found it interesting to consider which of the characteristics were the dominant ones for each decision maker. For example, the key decision maker for exterior cladding was the Board of Visitors (BOV). The source of their salience lies predominantly in the 
power that they have. They have the ability to prevent a project from progressing by rejecting the proposed building based on flaws found in the exterior appearance of the building. The structural engineer is the key decision maker for the superstructure, and his primary source of salience comes from legitimacy. If the structural engineer says something can or more importantly cannot be done, then his opinion will often overrule others because he is the expert and has critical knowledge other stakeholders do not have. Examining the relationships between stakeholders and within a stakeholder in these terms is a major area of future research for the construction industry.

As with most research endeavors, more questions were raised than answered. This project was no exception. It is the hope of this researcher that many will find meaningful and intriguing questions to pursue from this research. 


\section{Chapter 8: Limitations, Impacts, and Future Research}

As with any research, there are limitations, impacts, and areas for future research. This chapter will identify those for this research.

\subsection{Limitations}

There are several limitations that should be noted in this research. They are as follows:

1) The study that the HSCC is based on only goes through total installed cost. It does not include any operations and maintenance costs or demolition costs

2) The selection of people to perform inter-rater reliability analysis was very limited. More people should have identified and more stringent qualification criteria should have been established to be considered for selection

3) The indirect observation protocol was not validated in this research. It was identified as a method to find key decision makers, but requires validation

4) This framework is optimally designed for researchers with a vested interest in finding key decision makers for construction projects and with a higher than average knowledge of the construction field. It is not designed for someone with little knowledge of the field and with little personal interest in finding key decision makers

\subsection{Impacts}

The contribution of this research is the framework for identifying key decision makers for institutional owner capital projects. This will give future researchers a framework for identifying key decision makers so a tool such as a computer model for minimizing a facilities' TCO can be created for institutional owners.

\subsection{Future Research}

There are three main areas for future research. First, the HSCC and the study it is based on can be expanded. The Department of Commerce Study includes the total installed cost but does not consider the operations and maintenance costs. In order to meet the GSA's definition for green 
design, the current study will need to be expanded. If the study was expanded, the HSCC might change slightly, but the researcher does not expect that it will change significantly. Another item is expanding the number of buildings in the study and the building types. The DOC study only considered a single, office type building. By expanding the buildings included in the study, the generalizability of the HSCC would be greatly enhanced.

The second area is the framework itself. In its current form, the framework has only been tested on a single public agency. Testing the framework on a couple of other public agencies would enhance the generalizability of the framework itself. Along with increased testing, validating the indirect observation protocol needs to be done. The observation protocol is an important part of the framework, but it was not validated because it was not necessary for the institution investigated. Making the framework more robust so that a greater variety of people with different levels of interest will be capable of achieving reasonable results will make the adoption of the framework easier.

The last area for future research addresses some of the issues identified in chapter 7 . The affects of recording the interviews on the data obtained and determining the levels of salience of each key decision maker are necessary to make the framework more practical. In its present form, the framework is rather academic in nature. By addressing these two areas, the framework will move from being academic to practical. 


\section{References}

Beaver, E. (2000). "LCA and Total Cost Assessment." Environmental Progress, 19(2), 130-139.

Boussabaine, H. and Kirkham, R. (2004). Whole Life-cycle Costing: Risk and Risk Responses, Blackwell Publishing, Malden, MA.

Brand, S. (1994). How Buildings Learn: What Happens After They're Built, Viking, New York, NY.

Christiansen, J., and Altaweel, M. (2004). "Simulation of Natural and Social Process Interactions in Bronze Age Mesopotamian Settlement Systems." Society for American Anthropology 69th Annual Meeting, Montreal, Canada.

Census Bureau. (2008). “Annual Value of Federal Construction Put in Place 1993-2008." <http://www.census.gov/const/C30/federal.pdf> (June 20, 2009).

Construction Engineering Research Laboratory (CERL). (2009). “Micro PAVER Pavement Management System."

<http://www.cecer.army.mil/td/tips/product/details.cfm?ID=721\&TOP=1> (June 17, 2009).

Construction Engineering Research Laboratory (CERL). (2009). "Products/Capabilities." <http://www.cecer.army.mil/td/tips/browse/products.cfm?TOP=1\&TECHNAME=> (June 17, 2009).

Department of Commerce (DOC). (1999). Uniformat II Elemental Classification for Building Specifications, Cost Estimating, and Cost Analysis, US Department of Commerce, Washington, DC.

Department of Defense (DOD). (2006). Defense Aquisition Guidebook, Defense Acquisition University, Washington, DC., 38-74.

Department of Energy (DOE). (2007). Annual Energy Review 2007, Energy Information Administration, Washington, DC. 
Department of Energy (DOE). (2008). 2008 Buildings Energy Data Book, D\&R International, Ltd., Silver Spring, MD.

Ehlen, M. (1997). "Life-Cycle Costs of New Construction Materials." Journal of Infrastructure Systems, 3(4), 129-133.

Ellram, L., and Siferd, S. (1998). "Total Cost of Ownership: A Key Concept in Strategic Cost Management Decisions." Journal of Business Logistics, 19(1), 55-84.

Environmental Protection Agency (EPA). (1995). An Introduction to Environmental Accounting as a Business Tool: Key Concepts and Terms, Environmental Protection Agency, Washington, DC.

Executive Office of the President of the United States (EOPUS). (2008). "Budget of the United States Government." Executive Office of the President of the United States, Washington, DC.

Freeman, R. (1984). Strategic Management: A Stakeholder Approach, Pitman, Boston, MA.

Garvin, M. (2003). "Role of Project Delivery Systems in Infrastructure Improvement." Proceedings of the 2003 Construction Research Congress, ASCE, Reston, VA.

General Services Administration (GSA). (2008). Sustainability Matters, General Services Administration, Washington, DC.

Government Accountability Office (GAO). (2003). High Risk Series: Federal Real Property, Government Accountability Office, Washington, DC.

Government Accountability Office (GAO). (2004). Budget Issues: Agency Implementation of Capital Planning Principles is Mixed, Government Accountability Office, Washington, DC.

Government Accountability Office (GAO). (2005). Federal Real Property: Further Actions Needed to Address Long-Standing and Complex Problems, Government Accountability Office, Washington, DC. 
Government Accountability Office (GAO). (2007). High Risk Series: An Update, Government Accountability Office, Washington, DC.

Goodwin, P., and Wright, G. (2004). Decision Analysis for Management Judgment, John Wiley \& Sons Ltd, West Sussex, England.

Grossi, I. (2003). "Stakeholder Analysis in the Context of the Lean Enterprise." MS Thesis, Massachusetts Institute of Technology, Cambridge, MA.

Gurung, N., and Mahendran, M. (2002). "Comparative Life Cycle Costs for New Steel Portal Frame Building Systems." Building Research \& Information, 30(1), 35-46.

Hendrickson, C. (2000). Project Management for Construction: Fundamental Concepts for Owners, Engineers, Architects and Builders, Carnegie Mellon University, Pittsburgh, PA.

Hsieh, T., and Liu, H. (1997). "Multistage Heuristic Approach for Solving Infrastructure Investment Decision Problems." Journal of Infrastructure Systems, 3(4), 134-142.

International Facilities Management Association (IFMA). (2008). "Asset Lifecycle Model for Total Cost of Ownership Management: Framework, Glossary, and Definitions." International Facilities Management Association, National Association of State Facilities Administrators, Association of Higher Education Facilities Officers/APPA, Federal Facilities Council, Holder Construction Company, and Infrastructure Strategies. <http://www.ifma.org/tools/research/Asset_Lifecyle_Model.pdf> (Jan. 20, 2009).

Isaksen, S., and Gaulin, J. (2005). "A Reexamination of Brain storming Research: Implications for Research and Practice." Gifted Child Quarterly, 49(4), 315-329.

Johansson, D. (2009). "The Life Cycle Costs of Indoor Climate Systems in Dwellings and Offices Taking Into Account System Choice, Airflow Rate, Health, and Productivity." Building and Environment, 44(2), 368-376.

Kane, G. and Velury, U. (2004). "The Role of Institutional Ownership in the Market for Auditing Services: An Empirical Investigation." Journal of Business Research, 57(9), 976-983. 
Keysar, E. and Pearce, A. (2007). “Decision Support Tools for Green Building: Facilitating Selection Among New Adopters on Public Sector Projects." Journal of Green Building, 2(3).

Klotz, L., Horman, M., and Bodenschatz, M. (2007). "A Lean Modeling Protocol for Evaluating Green Project Delivery." Lean Construction Journal, 3(1), 1-18.

Kosareo, L., and Ries, R. (2007). "Comparative Environmental Life Cycle Assessment of Green Roofs." Building and Environment, 42(7), 2606-2613.

Liu, J. (2009). "Parametric Model for Assessing Factors that Influence Highway Bridge Service Life," Doctoral Dissertation, Virginia Tech, Blacksburg, VA.

Ljungqvist, A., Marston, F., Starks, L., Wei, K., and Yan, H. (2007). “Conflicts of Interest in SellSide Research and the Moderating Role of Institutional Investors." Journal of Financial Economics, 85(2), 420-456.

Macal, C., and North, M. (2005). "Tutorial on Agent-Based Modeling and Simulation." Proceedings of the 37th Conference on Winter Simulation, Winter Simulation Conference, Orlando, FL., 2-15.

Macal, C., and North, M. (2006). "Tutorial on Agent-Based Modeling and Simulation Part 2: How to Model With Agents." Proceedings of the 38th Conference on Winter Simulation, Winter Simulation Conference, Monterey, CA., 73-83.

Matvos, G. and Ostrosvsky, M. (2008). "Cross-Ownership, Returns, and Voting in Mergers." Journal of Financial Economics, 89(3), 391-403.

Merriam-Webster. (2009). "Merriam-Webster Online Dictionary." <http://www.merriamwebster.com/dictionary/key> (May 17, 2009).

Mitchell, R., Agle, B., and Wood, D. (1997). "Toward a Theory of Stakeholder Identification and Salience: Defining the Principle of Who and What Really Counts." The Academy of Management Review, 22(4), 853-886. 
Morse, J. (1995). "The Significance of Saturation." Qualitative Health Research, 5(2), 147-149.

Murry-Webster, R. and Simon P. (2006). “Making Sense of Stakeholder Mapping." PM World Today, 8(11), 1-5.

National Research Council (NRC). (2004). Investments in Federal Facilities: Asset Management Strategies for the 21st Century, National Academies Press, Washington, DC.

National Research Council (NRC). (2008). Core Competencies for Federal Facilities Asset Management Through 2020, The National Academies Press, Washington, DC.

Office of Management and Budget (OMB). (2006). Capital Programming Guide, Office of Management and Budget, Washington, DC.

Pearce, A., Garvin, M., and Sanford-Bernhardt, K. (2008). "Sustainability and Capital Projects: Modeling the Emergent Property of Total Cost of Ownership." Proposal to the Environmental Sustainability Program, Engineering Directorate, National Science Foundation, March 2.

Plucker, F. (1990). "The Use and Validation of Qualitative Methods Used in Program Evaluation." Annual Research Conference of the California Association of Community Colleges, California Association of Community Colleges, Monterey, CA.

Virginia Tech (VT). (2008). "Facilities Services." <www.facilities.vt.edu/index.asp> (April 22, 2009).

Virginia Tech (VT). (2009). "Project Document Turnover Checklist." <www.facilities.vt.edu/documents/Project_Doc_Requirements.pd> (May 14,2009).

Wasserman, S. and Faust, K. (1994). Social Network Analysis: Methods and Applications, Cambridge University Press, New York, NY. 


\section{Appendix A: Research Methodologies}

\begin{tabular}{|c|c|c|}
\hline $\begin{array}{c}\text { Research } \\
\text { Methodology }\end{array}$ & Strengths & Weaknesses \\
\hline \multirow{5}{*}{ Surveys in general } & $\begin{array}{l}\text { Simple approach to study of } \\
\text { attitudes, values, or beliefs }\end{array}$ & $\begin{array}{l}\text { Data is affected by respondents } \\
\text { memory, knowledge, experience, } \\
\text { etc. }\end{array}$ \\
\hline & $\begin{array}{l}\text { Very adaptable to collect } \\
\text { information from almost any } \\
\text { human population }\end{array}$ & $\begin{array}{l}\text { Respondents won't necessarily } \\
\text { report their true beliefs (e.g. } \\
\text { people want to be seen in a good } \\
\text { light) }\end{array}$ \\
\hline & $\begin{array}{l}\text { allows for comparisons to be } \\
\text { done }\end{array}$ & $\begin{array}{l}\text { capturing the quantifiable data } \\
\text { needed }\end{array}$ \\
\hline & & $\begin{array}{l}\text { Having to go back to respondents if } \\
\text { more data is needed }\end{array}$ \\
\hline & $\begin{array}{l}\text { High amounts of data } \\
\text { standardization }\end{array}$ & $\begin{array}{l}\text { Only getting answers for questions } \\
\text { that one has thought of }\end{array}$ \\
\hline \multirow{3}{*}{$\begin{array}{c}\text { Postal/self- } \\
\text { administered surveys }\end{array}$} & $\begin{array}{l}\text { Often the easiest way to } \\
\text { collect data from a large set of } \\
\text { people }\end{array}$ & Low response rate \\
\hline & $\begin{array}{l}\text { Have the capacity to be } \\
\text { extremely efficient for } \\
\text { collecting large amounts of } \\
\text { data in a relatively short } \\
\text { period of time at relatively low } \\
\text { cost }\end{array}$ & $\begin{array}{l}\text { Ambiguities and misunderstanding } \\
\text { of survey questions are not } \\
\text { detected }\end{array}$ \\
\hline & $\begin{array}{l}\text { Allows anonymity which } \\
\text { encourages frankness }\end{array}$ & $\begin{array}{l}\text { respondents may not take the } \\
\text { survey seriously }\end{array}$ \\
\hline \multirow[t]{2}{*}{ Interviews } & $\begin{array}{l}\text { Interviewer can clarify } \\
\text { questions }\end{array}$ & $\begin{array}{l}\text { Data may be affected by the } \\
\text { personality characteristics of the } \\
\text { interviewer }\end{array}$ \\
\hline & $\begin{array}{l}\text { interviewer's presence can } \\
\text { encourage participation and } \\
\text { involvement }\end{array}$ & $\begin{array}{l}\text { respondents may feel less open } \\
\text { since the survey is not anonymous }\end{array}$ \\
\hline
\end{tabular}




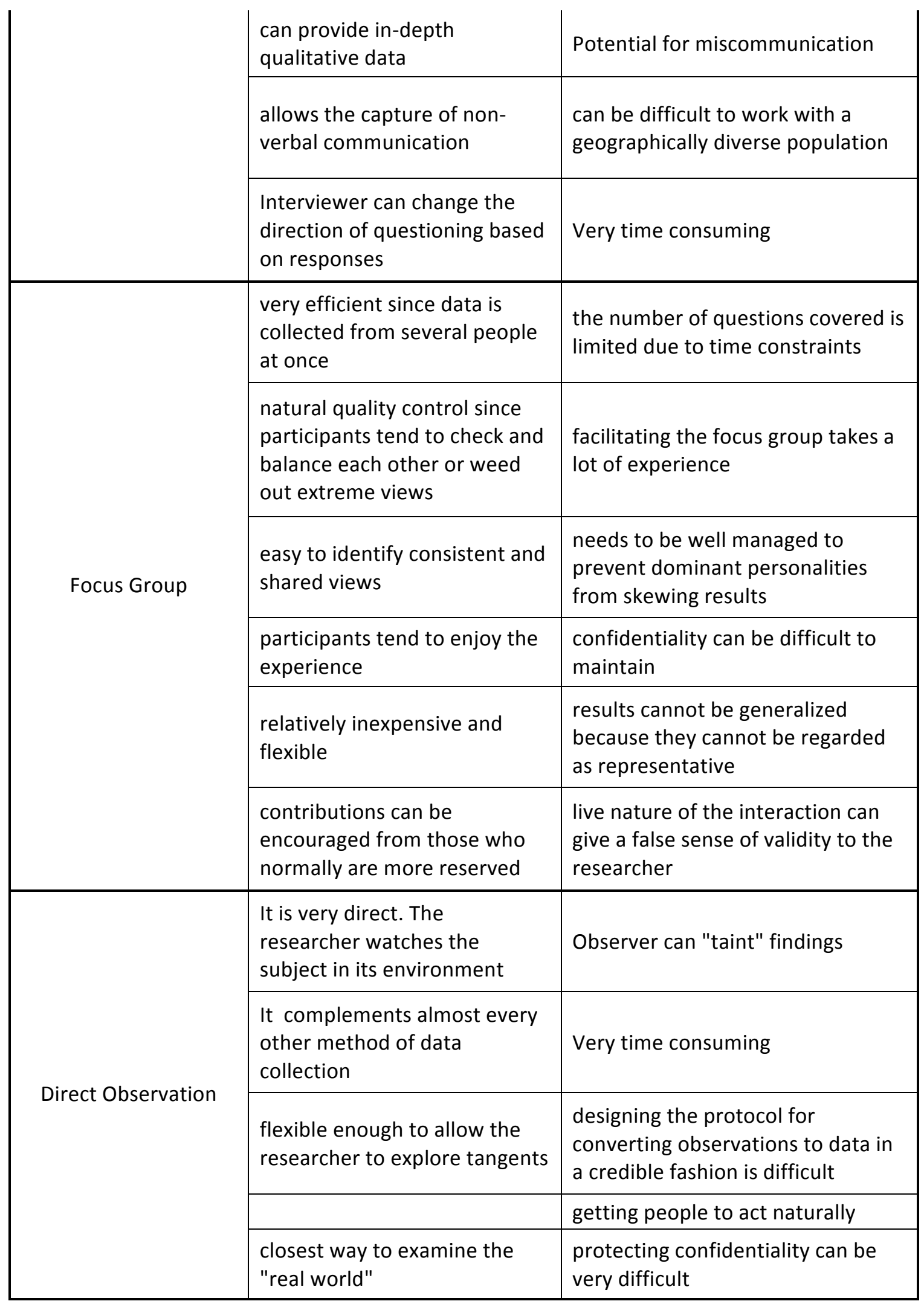




\begin{tabular}{|c|c|c|}
\hline \multirow{6}{*}{$\begin{array}{l}\text { "Trace" Measures (e.g. } \\
\text { Accretion, Erosion, } \\
\text { Document review) }\end{array}$} & good at collecting usage data & $\begin{array}{l}\text { Context can be difficult to identify } \\
\text { which may possibly result in } \\
\text { incorrect findings }\end{array}$ \\
\hline & $\begin{array}{l}\text { non-obtrusive and non- } \\
\text { reactive. }\end{array}$ & $\begin{array}{l}\text { Apparent link between cause and } \\
\text { effect may be affected by unknown } \\
\text { forces/events }\end{array}$ \\
\hline & not reliant on people & $\begin{array}{l}\text { linking the population studied to } \\
\text { where it came from may be } \\
\text { difficult or impossible }\end{array}$ \\
\hline & $\begin{array}{l}\text { capitalizes on data that is } \\
\text { already available }\end{array}$ & $\begin{array}{l}\text { shortcomings in available data are } \\
\text { hard to overcome }\end{array}$ \\
\hline & $\begin{array}{l}\text { allows the researcher to } \\
\text { maintain neutrality }\end{array}$ & \\
\hline & $\begin{array}{l}\text { provides valuable cross- } \\
\text { validation of other measures }\end{array}$ & \\
\hline \multirow{3}{*}{ Content Analysis } & unobtrusive & limited availability of documents \\
\hline & $\begin{array}{l}\text { records are permanent leading } \\
\text { to the option of replicating } \\
\text { studies }\end{array}$ & $\begin{array}{l}\text { may be difficult or impossible to } \\
\text { account for biases or distortions } \\
\text { since the document may not be } \\
\text { written for the same purpose as } \\
\text { the research question }\end{array}$ \\
\hline & $\begin{array}{l}\text { low cost form longitudinal } \\
\text { analysis where a series of } \\
\text { documents are available }\end{array}$ & $\begin{array}{l}\text { difficult to assess causal } \\
\text { relationships }\end{array}$ \\
\hline
\end{tabular}




\section{Appendix B: Document Analysis Protocol}

\section{Other Data Instrument Inputs}

1) None

\section{$\underline{\text { Potential Outputs }}$}

1) List of potential key decision makers

2) List of candidate projects

3) List of possible meetings

4) Meeting administrator's contact information

$\underline{\text { Items Needed to Execute }}$

1) IRB approval (if applicable)

\section{Introduction:}

Each of the following sections provides some general guidelines for finding one of the potential outputs of this protocol. For all of the sections, the researcher will be looking for documents on the web or paper records found at the organization in question. Generally, one should try to obtain the information for all of the sections unless only certain outputs are needed.

The overall goal of this research is to identify key decision makers. This protocol feeds seeding information to the other protocols in the framework in order to identify key decision makers.

\section{Decision Makers:}

The goal for the researcher is to look through the organizational charts and operating procedures to determine who makes the decisions for the six largest building systems found on the High System Cost Chart (HSCC) (See Appendix A). Specifically, who makes decisions that affect each system's characteristics or properties. Some example statements to look for are, 

is solely responsible for evaluating and approving ", "group $x$ shall follow the specifications provided by ", or " signed off on ." Any phraseology similar to these examples should indicate who makes decisions concerning each building system. The researcher then records the person/office that makes the decision. People designated by one of the above phrases or a similar phrase can be considered a key decision maker.

It still may be very difficult to determine if the person is the actual decision maker because documents don't indicate if a decision maker is a "rubber stamp" type or not. An example of a "rubber stamp" decision maker is a superior who simply signs whatever his subordinates send him without looking at it. The researcher should not worry about this eventuality too much but focus on generating a list of names who might be decision makers.

Some documents to specifically look for are as follows:

1) Organization charts or similar charts that describe roles and responsibilities

2) Standard operating procedures, particularly for the construction process

3) Organizational websites

4) Annual reports

5) Historical project files

\section{Candidate Projects}

Institutional owners will normally have a report that lists the current projects and where each one stands in terms of completion. Searching the facility department's website using terms "current projects" or "construction projects" should yield some of these documents.

Often along with the current projects, the project manager will be listed. It is very important to capture the project manager along with the project because they will often be the starting point for the interview protocol.

The last step of this section is to create a map of the current projects (Figure 1). Depending on the institution, it may or may not make sense to sort laboratory buildings and office buildings. 
The major categories that one should aim to map are the stage of the construction lifecycle the building is in, the project delivery method, and the gross square footage.

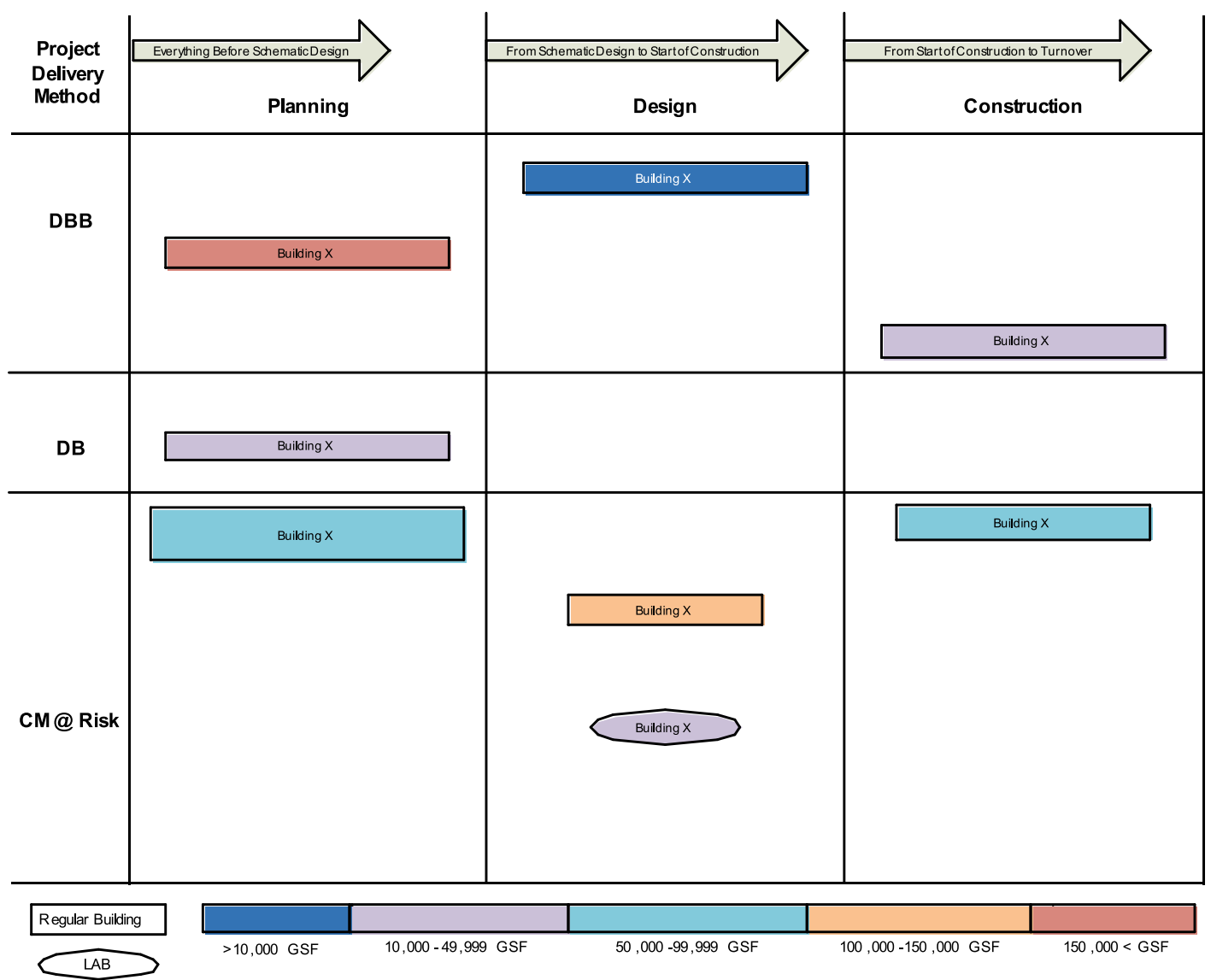

Figure 1: Example Project

\section{List of Possible Meetings}

Construction process documents or other documents that have meetings listed on them can normally be found by searching "construction project meetings" or "project meetings" on the facility department's website. The search may not yield a list of current or future project meetings, but at least it should identify typical project meetings for any project executed by the institutional owner. These typical meetings are sometimes described in the policy documents of the organization. At the very least, the researcher will know the standard meetings that may be beneficial later on. 


\section{Meeting Administrators Contact Info}

Some of the same documents that list the meetings typically have at least the necessary attendees listed as well. They will typically identify offices such as the University Architect or Project Manager, but the actual person who fills the office can then be tracked down under the "staff" or "contact us" sections of the website. If offices are not identified or if there are multiple people in the office, write down all the potential meeting administrators. This information can then be used in the interview process. 


\section{Appendix C: Semi Structured Interview Protocol}

\section{Other Data Instrument Inputs:}

1) List of recent projects

2) List of potential key decision makers

\section{Potential Outputs:}

1) Validated key decision maker list

2) List of potential key decision makers

3) List of potential meetings to attend

Items Needed to Execute

1) Key definitions sheet

2) High System Cost Chart

3) Copies of Decision Maker Listing sheet

Instructions for Interviewer:

General instructions for conducting the interview will be in a normal font and specific items to ask the interviewee will be italicized. To start the interview, read the purpose statement to the interviewee. Below is an example statement.

This interview is being conducted to collect data for an NSF funded research project at Virginia Tech. It is the aim of the researchers to develop a tool for optimizing investment in sustainable facility features. All responses to this survey will be kept strictly confidential, and if at any point you do not wish to continue participating, you may leave with no consequence.

Ask the interviewee if there are any questions before proceeding.

Hand the interviewee a copy of the High System Cost Chart (HSCC) and describe the overall research objective. You will also need to have the definitions sheet with you, but do not give it to the interviewee yet. An example script can be found below. 
In order to optimize investment in sustainability, it is important to know who makes decisions about building systems with the largest impact on the Total Cost of Ownership of the facility. The High System Cost Chart is a depiction of the top 6 most expensive building systems according to a study done by the US Department of Commerce. These six systems are a focus of this research.

Next, establish a standard definition for some of the key terms. See the example script below.

Before we get to the interview questions, it is important for you to understand some definitions used in this research. The definitions are as follows:

1. A key decision maker is the person or group who has the most influence on the system selection or system characteristics. If it is a group, the group must act like a single entity. For example, imagine a software company trying to sell its product to an institutional owner. The procurement representative, Lawrence, who interacts with the software company's sales representative may not have the authority to actually purchase the software. Lawrence can only send a recommendation to his superior, Ashton. If Ashton just rubber stamps what Lawrence recommends, Lawrence is the key decision maker. However, if Ashton takes the recommendation INTO CONSIDERATION BUT makes his own decision, then the he is the key decision maker.

Hand the interviewee a sheet with these definitions after reading them aloud and ask if there are any questions about the definitions.

Now begin the interview with the following questions as they seem relevant. You can remind them that the definition of each system is on the definitions sheet if they need it.

Were you involved in any of the following projects: (Hand the interviewee the list of recent projects)?

Of those projects, which one are you most familiar with? 
If they are not familiar with any, ask them the following ALT. questions and skip to the name generation part of the interview:

ALT: "Think about some of the recent projects that you were involved in. Which one would you consider "typical" of your organization?"

ALT: What are some of the characteristics that made it "typical" in your opinion?

ALT: Would you consider the project successful? Why or why not?

Would you consider <insert project name> to be a relatively typical project for your institution? If not, why?

\section{NAME GENERATION:}

You may want to hand the interviewee the Decision Maker Listing sheet and have them fill it out themselves. If they need more sheets, give them more. 
Think about who was involved in making decisions that affect the characteristics of the 6 building systems on the HSCC for the ICTAS II project. For each of the following systems, please list everyone who was involved in making decisions.

1) For the exterior enclosure?

2) For the HVAC system?

3) For the electrical system?

4) For the superstructure?

5) For interior finishes?

6) For conveyance?

Now, I would like you to examine the lists you created. Cross out anyone who is not part of the owner organization (architects, outside engineers, etc.). 
Now, could you please rate the remaining names according to the amount of influence you perceive them to have on each system, 10 being the greatest amount of influence and 1 being the least amount of influence.

Do you know of any meetings that the decision makers you identified would attend in the near future? If not, who would be a good person to ask to find out?

Can you give me the contact information for that person?

This interview is complete. Do you have any final questions?

Thank you very much for your time. 


\section{Decision Maker Listing Sheet}

Think about who was involved in making decisions that affect the characteristics of the 6 building systems on the HSCC for the ICTAS II project. For each of the following systems, please list everyone who was involved in making decisions.

1) For the exterior enclosure?

2) For the HVAC system?

3) For the electrical system?

4) For the superstructure?

5) For interior finishes?

6) For conveyance? 


\section{Interview Definitions}

1. Key Decision Maker - the person or group who has the most influence on the system. If it is a group, the group must act like a single entity

2. Exterior Enclosure - exterior wall, windows, and doors

3. HVAC - energy supply, heating and cooling generation, distribution systems, terminal \& package units, controls and instrumentation

4. Electrical - service \& distribution, lighting \& branch wiring, communication \& security

5. Superstructure - floor and roof construction

6. Interior Finishes - wall, floor, and ceiling finishes

7. Conveyance - elevators, lifts, escalators, and moving walks 


\section{Appendix D: Indirect Observation Protocol}

\section{Other Data Instrument Inputs}

1) List of possible meetings

2) List of potential key decision makers

3) Contact info for meeting administrator

\section{Output}

1) Validated key decision makers

\section{$\underline{\text { Items Needed to Execute }}$}

1) Research Information Sheet

2) Notification of approval to attend by meeting administrator

3) Reference by someone else in the organization (optional)

\section{Introduction:}

The meetings that the researcher should attend should have been identified between the document review and interview process. Once the meetings have been identified, the researcher needs to contact whoever is responsible for running the meeting to obtain permission to attend it. A copy of the research information sheet should be sent with the request to substantiate the reason for attending. Ideally, a reference from someone else in the organization will also have been obtained and included in the request. Once the request has been approved, data collection can proceed.

Before arriving at the meeting, be sure to develop a list of attendees and their roles. If there are multiple people with the same first name and their last name is not clear, arbitrarily assign a person \#1 and person \#2 for data collection during the meeting. Either before or at the end of the meeting, ask either the meeting administrator or one of the two people in question to clarify who is who. 


\section{AT THE MEETING:}

Be sure to arrive at least 15 minutes early so you can find the meeting room and start putting names and faces together. Ideally, you should go around the room as people arrive and exchange business cards. This will help put a name with the face and give you contact info if further follow up is necessary. If time permits, quickly sketch the meeting room with where each person is sitting. It may be beneficial to bring someone along to do this for you.

At the meeting, the researcher should begin listening for phrases like "I will be responsible for __, "You take the lead with item___ o _ or similar phrases where someone is indicated to make decisions concerning one of the building systems of interest. Anytime someone is delegated a responsibility for or makes a statement concerning one of the six HSCC systems, the researcher should record that person/office by putting a tick mark by their name. Once the meeting is concluded, the key decision makers previously identified should have the greatest number of tick marks by their name. 


\section{Appendix E: Interview Transcript A}

Interviewer: All right. So, this shouldn't take too long. I have only got about 6 or 7 questions.

Bob $^{1}$ : Okay.

Interviewer: But there is a fair amount - well, there is potentially a fair amount of writing that will need to be done. So the first thing to start off with is I'm going to show you this, what we call a high system class chart, and that chart is basically a breakdown of building systems according to the Uniformat II. Are you familiar with Uniformat at all?

Bob: No.

Interviewer: Well it's basically a specification organization method. Normally there is - well, a lot of people have been using MasterFormat and it has unit, or section 1, 2, 3, 4 through 16.

Bob: That's the one I'm familiar with.

Interviewer: Yeah. So Uniformat is like that, except for it's organized according to work packages a little bit more.

Bob: Okay.

Interviewer: As you can see, electrical is in one group, so anything electrical is in that group. HVAC is in one group, and it's just, it's easier from a work-packaging standpoint, and also, I think, a cost-estimating standpoint, because you're looking for similar things.

Bob: Right.

Interviewer: So, basically, this is a summary of a study that the Department of Commerce did when they looked at an 8-storey office building that only had a footprint of about $6,000 \mathrm{ft}^{2}$. But they went through and they cost it out, each of the systems, using this Uniformat method, all

\footnotetext{
${ }^{1}$ Names have been substituted to preserve subject anonymity
} 
the way through total installed cost. So it has all the construction materials, and they even included something for labor and the contractor markup.

Bob: Okay.

Interviewer: Okay?

Bob: $\mathrm{Mm} \mathrm{hmm.}$

Interviewer: So, the first question is, based off of your experience, are those systems - are they representative of how expensive each of those are?

Bob: Okay, I'm having trouble here, because I'm not sure with the colors which is - are they in order?

Interviewer: They are in the same order. Yeah.

Bob: Okay.

Interviewer: I didn't have a colored printer, sorry.

Bob: What are you calling "conveying"?

Interviewer: Conveyance is like - here's a sheet of definitions, sorry.

Bob: Okay.

Interviewer: Conveyance is elevators, lifts, escalators, that sort of thing.

Bob: I didn't know if that was that type of conveying or like the management component, see.

Interviewer: Okay, no. These should all be like, building systems, physical building systems.

Bob: And the superstructure is the exterior?

Interviewer: It is everything from the foundation up. So that would be like, your steel beams, or, in this building, I believe they're concrete forms. The main structural member. 
Bob: Exterior enclosure. So this is the envelope, here. Because I know that tick, that may be a little more because of the Hokie stone.

Interviewer: $\mathrm{Mm} \mathrm{hmm.}$

Bob: So I think it would depend on, like at the Corporate Research Center, this is probably more true than it would be on campus, because I know Hokie stone adds a premium just because of the labor. It's labor intensive, so...

Interviewer: Okay. But in general, looking at those -

Bob: That chart looks pretty balanced.

Interviewer: It looks pretty balanced according to total installed cost. Like, what you've seen.

Bob: Far as I know. I don't work a lot on the budget side, but just from when we're doing value engineering I know these are some of the places that we would start cutting, would be -

Interviewer: Okay.

Bob: Probably in some of the lower cost items.

Interviewer: That's awesome. So the followup question to that is, if you were to consider the same systems from an operations and maintenance standpoint -

Bob: $\mathrm{Mm} \mathrm{hmm}$.

Interviewer: Are they still pretty representative? Or would you change the order, like, which ones cost more or less? Would you add anything to them?

Bob: I guess the other systems - you're looking at that - well, the other thing you're going to run into - are you talking about lab facilities, or office facilities? Because this could change depending on function of facility.

Interviewer: We're going to just consider ICTAS I. 
Bob: Okay, because it is a lab facility. So, maintenance costs are coming in from maintaining program-specific equipment. And again, I don't manage the budget for physical plants, so I don't know what their costs are as far as custodial services or... But I know from my standpoint, our costs are coming in with maintenance agreements for HVAC - I mean, the air and vacuum systems -

Interviewer: Okay.

Bob: The autoclaves, the program-specific equipment in the building, the fume hoods, those type things that you would not have in an office building. So that's why I was asking on that front, because you would not have those associated costs in William's Hall.

Interviewer: Right, right. So the HVAC component might be a little bit -

Bob: The HVAC, see again, I don't know because that's handled through the University, and a person that you would probably want to talk with there would be Sam, who is the director of facilities, and he would know more about the actual building costs, the envelope, and the mine would be more from a management standpoint of the interiors and the, again, the program-specific equipment. So I couldn't speak to those, but I know they do have preventive maintenance on the HVAC system, so I'm assuming that that cost is a premium because that person is dedicated in this building, particularly to the MEPs.

Interviewer: Okay. Alright. Perfect.

Bob: And probably, interior finishes goes down. So I would think you would have less of a maintenance cost. I mean, as far as building it, this is probably accurate, but interior finishes would go down as far as maintenance. I think it would be a lot less than these others.

Interviewer: Okay.

Bob: Does that make sense?

Interviewer: Yep, makes perfect sense. 
Bob: And even at that, the elevators may pick up a little bit, because that's where I have a lot of trouble - with just the elevators in general I think. Just the maintenance on those is probably a little more.

Interviewer: Okay, so elevators or conveyance would probably go up, interior finishes would go down, electrical would fluctuate probably.

Bob: I'd say the - we don't have a lot of issues with maintenance on electrical, no. We do have a lot of renovation work, but you're not looking at that. You're looking at what was in the project and what it cost to maintain that, right?

Interviewer: Or, basically, I'm more looking like this study goes up to total installed costs. I kind of want to just think about and capture your thoughts on from installed cost to the end, to like, demolition.

Bob: Where we run into a problem, if you're going there, which is different than maintenance, is renovations, because architects tend to miss a lot of electrical needs. We have spent a tremendous amount of money already, and we have only been in here since April, on adding electrical outlets that were missed in design or where the program needs have changed. And I think no matter how much you plan, it's really hard to hit the mark on what electrical needs you're going to have. So we do spend a lot of money on electrical upgrades.

Interviewer: Getting electrical - okay. Good. Perfect.

Bob: Again, we don't do a lot with - I don't do a lot with the elevators. The other systems as I mentioned that would be our cost, where we have quite a bit of cost, but you've got that captured already there. Interior finishes other - again then, somebody decided just last week they wanted the downstairs wall painted red instead of white, and that's just going to come with personalities, but that's still minimal. The superstructure, I can't - if the roof is installed correctly, I would think you wouldn't have a lot of issues with that, to the end. You know? It's going to be a cost at the end of the warranty period, for if they have to go and do repairs or replacing it. But as far as on a continuum, I can't think that there would be a lot of cost 
associated with that part of it. Floors, and you're not talking carpets and those kinds of things, you're talking -

Interviewer: Nope, that's yeah, an interior finish - would be -

Bob: That's in an interior finish -

Interviewer: Yeah, that would be the interior -

Bob: So not in the superstructure.

Interviewer: No, no. The superstructure floor would be the -

Bob: But still, with the interior finishes, again, if the carpets are maintained as they should be, cleaned at least once a year, and that's going to be a minimal cost versus replacing it. So I think your costs are going to be correlated with how well the building's managed. Does that make sense?

Interviewer: Oh yeah.

Bob: Because if you have someone cleaning your carpets as you're supposed to be, the carpets are going to last longer. If you have someone changing the filters in the HVAC system, as it should be, the cost is going be lower - even though the up-front cost for the filters is more, in the long run it's going to pay off because the equipment is going to run longer.

Interviewer: Right.

Bob: So I think the building costs directly correlate with how well the building's managed.

Interviewer: Okay. If we assume that, you know, standard operating or maintenance procedures are done, and someone doesn't like, slack off, then -

Bob: Right, like I said, I think the interior costs would go down. I think the electrical costs could go up just because of the additional work, if you're including that. It's not so much maintenance, but it's just adding. Superstructure I think would probably stay the same, or it could even go down. Interior finishes, again, said it would go down. Elevators I think could 
possibly go up in percentage with the other systems. The exterior enclosure, and there again, if it's installed properly - we did have issues with the effervescence - so, if that was done properly, that, I think, would be minimal.

Interviewer: Okay.

Bob: Just because that's why they used the Hokie stone. It's very minimal maintenance if it's done properly. And so I think that would be a less. It's going to be more up front because of the type of structure it is, but because of the type of structure, it will be less in the long run. So I think the cost will pay for itself in maintenance every year. But, if it's not installed properly, then there is a huge cost associated.

Interviewer: Okay, okay.

Bob: Assuming it's installed properly.

Interviewer: Right.

Bob: It's good. I would think it would be a lot less, percentage-wise.

Interviewer: Okay, excellent. Now we are going to get to the, I guess, second part, where that was kind of like - just to get an idea of the systems and the general gist of what I'm doing for the research. This next part, I'm specifically looking - I'm trying to identify key decision makers for our construction project, and how this plays into that is I'm trying to find key decision makers, or people who make decisions about these systems here.

Bob: Okay.

Interviewer: Because - because they comprise basically the majority of the cost of a system, I'm trying to - I'm just going to look for those people for now.

Bob: Okay.

Interviewer: So, some things to keep in mind, we're going to assume that all the guidelines and codes, requirements, are all met. 
Bob: Okay.

Interviewer: I know that Virginia Tech has a whole -

Bob: Thing that everybody else does -

Interviewer: Thing that everyone has to meet - these are the specifications, guidelines for Virginia Tech, you know. So, if we take all that sort of stuff as a given, we're trying to look for people who make decisions - because there's still wiggle room, you know.

Bob: Oh, there's lots, and there's lots of people.

Interviewer: There's lots of wiggle room for each of these systems, but there are two other things.

Bob: And are you looking specifically for Virginia Tech? Because that's where I'm coming back to, so you're looking at Virginia Tech facilities.

Interviewer: Yeah, I'm looking at Virginia Tech facilities, and I'm specifically looking at this building, okay? So this building, ICTAS I, using the - all the codes and guidelines as a given, and then there are two other concepts that I need to quickly communicate to you. The first one is there's - I'm not looking for a rubber stamp decision-maker.

Bob: Right, I understand because I'm in that process, so I understand where you're coming from.

Interviewer: Okay, yeah. I'm not like - if there's a subordinate who, you know, makes a recommendation, and the boss is kind of like, "Whatever he says," then it would be the subordinate who makes the decision, as opposed to the boss making the decision, so-to-speak.

Bob: Right. And I'm pulling something out just so you can get an idea. From - I'm the end user, and that's my role because I'm the end user rep, and I do go to all the construction meetings. We got to help take this CM @ Risk, so we all have voice in that. I was trying to find the - it's not in here, it's not filed where it's supposed to be. But we just recently went through this process of determining - ah, here we go. So these are the review comments. So you can see, we went 
through with the A\&E team, and a construction management team, and we being ICTAS Administration, a representative from Capital Design and Planning and - are you familiar with Capital Design and Planning at Virginia Tech?

Interviewer: The -

Bob: The CDC, Planning Design and Construction.

Interviewer: The department over in facilities?

Bob: It's Sterrett.

Interviewer: Yeah.

Bob: Right.

Interviewer: Yeah.

Bob: Okay, so they have a project manager and an assistant project manager, and that's the University's voice for the construction side of things. And you're looking only at constructability? Or are you looking at finance? Or...?

Interviewer: A key decision maker is defined as anyone who makes -

Bob: Has a decision -

Interviewer: Who - who significantly impacts the characteristics of this, not necessarily the cost

Bob: Right.

Interviewer: But whoever determines the characteristics of these steps.

Bob: Okay, because that's just what I wanted to clarify, because there's different - because we can make a recommendation but the budget may dictate that it's not...

Interviewer: Right. 
Bob: So you can see these are just some notes that I had pulled out. This is from Christine, and let me see what his - who Christine is. He apparently worked with reviewing the mechanical systems. So Christine is apparently someone that's in the maintenance side of physical plant. So he had a voice in - he's got down - he's commenting on the air compressors and the sensor controller, so he apparently works with the Siemens piece of the mechanical systems.

Interviewer: Okay.

Bob: And this was Phil, who was the AIA representative, and he's responsible for ADA. So -

Interviewer: Okay.

Bob: So he had a component in the decision making, so he reviewed the project. These are all from our design reviews. We all reviewed the plans. We submitted one from ICTAS Administration. And so what they do is they take these, and this is Lizzy, and he is with the - I'm thinking he's working with the commissioning component and the sustainable energy component. So their office had some say. So what these do, these even go out to - there's a whole list and that's why I was asking - Planning Design and Construction could tell you who the list goes out to, and they would be a good resource - but it goes out to the people who maintain the system's invisible plant, so it would be the supervisors of those crews. So there will be an electrician representative there, and that's usually $\underline{\text { Dan. }}$. There would be a mechanical person there, and that's usually $\underline{\text { Sam. }}$.

Interviewer: That's mechanical?

Bob: Yeah. That's Sam. Don works with commissioning. He would be reviewing Bill. And this is one thing I think is really good, he's the custodial supervisor, and he gets to review the finishes because of, you know, knowing that this is going to be a maintenance problem, or if there is a lot of glass in the building, and he knows that it's a misfit because they don't clean glass. He has some say in that. Like, recently, from ICTAS I to ICTAS II we have done away with stainless steel toilet dividers because Bill says it costs too much to maintain them.

Interviewer: Oh, okay. 
Bob: We're going with the more plastic-type divider in ICTAS II. So he has a voice.

Interviewer: What was his name again?

Bob: Bill. And then John is the architect for interior finishes. She works closely with me. She and I will pick out the furniture and the finishes. We have already done that. In fact, between the architects and ICTAS and the interior designer, we picked all the colors and all the finishes.

Interviewer: Okay.

Bob: Let me think, who else is there? What other systems do you have? There is a representative from - Zoe used to be, and I'm not sure who it is - Juilie, let's just put Juilie and that will cover it. Juilie oversees the Hokie stone installation process. So he would review Hokie stone, anything dealing with Hokie stone.

Interviewer: Juilie, what was his last -

Bob: Bishop is from the Hokie passport office, so she reviews the security system drawing. She and I work closely together with that, which may not sound like a big deal but it was a big deal in this building, because you need someone that knows the user interface to help with the design of the security system, and that's Bishop. And let's see, and then there's a representative from Otis, and I don't know his name.

Interviewer: What's Otis?

Bob: The elevators.

Interviewer: Oh.

Bob: Because Otis has the contract for all elevators on campus.

Interviewer: Okay.

Bob: So it will be an Otis-supported elevator on campus. 
Interviewer: Who - I mean obviously Virginia Tech has to have someone who reviews the elevators, or makes sure that -

Bob: Who from Virginia Tech? They have - that's their Otis representative. There is a person assigned to Virginia Tech, and I don't know their name.

Interviewer: But Virginia Tech doesn't have like, their own person who just kind of makes sure -

Bob: It's contracted out, same with Siemens.

Interviewer: Oh, okay.

Bob: Yeah, so the HVAC controls are - so, well, aㅡ, I guess the elevators fall back to Dan.

Interviewer: Back to Dan?

Bob: Yeah.

Interviewer: Okay.

Bob: She does those, too.

Interviewer: Okay. Who would make decisions about the superstructure?

Bob: The structure... Who is the structure person? And here again, that probably falls back to the project manager, and what they do is they - that is part of the AE team. There's not really anybody at Virginia Tech that I know of, except they coordinate with the project manager from Planning Design and Construction. And they hire a consultant, usually either from the AE firm or an independent consultant.

Interviewer: Okay.

Bob: And then there's also the commissioning person that oversees some of that. Most of the time though, the commission components are only the MEPs.

Interviewer: Okay. 
Bob: Yeah but to my knowledge, there is not anyone - the structural engineer with the AE team is who oversees the substructure.

Interviewer: Okay.

Bob: And the superstructure.

Interviewer: There is no one from ICTAS necessarily who says anything about structure? Okay. Cool.

Bob: Well, yes, no. We will give them our vibration requirements, yes. So that's us, that's from our side. So Ellie, he's our lab manager, he will review the - will work closely with the - they have a lab designer on ICTAS II, they didn't on this one. I wish they had. But they will ask us for the spec sheets, and we will review the spec sheets, check for any electrical requirements, special electrical, special exhaust, and that's - Ellie and I do that, and we check for vibration requirements.

Interviewer: And that normally goes in with like the program requirements, or something like that.

Bob: Well, it doesn't go in with the program. It goes back when we actually were doing the design of the labs. It was during like, the working drawings.

Interviewer: Oh, okay. So after schematic drawings happen you realize, "Okay, this building is actually going to happen."

Bob: Right. But it's not the construction drawings.

Interviewer: But it's not the CD - okay, okay. Alright. Excellent.

Bob: And the tricky part there, is you don't always know who is going to be assigned to the building.

Interviewer: Right. So you have the - 
Bob: I'm just going to turn this off because it's distracting me, so. I need to reset that thing. It's got that slide show thing that keeps switching, so it's -

Interviewer: Oh, yeah. Yeah. I'm the same way, whenever - anytime I go - I don't watch TV - so anytime I go out with my friends or something, I'm like, "Wow!"

Bob: That's what's going on in there!

Interviewer: Yeah, exactly. It's like, "Wow, so this is the commercial everyone's been talking about." Yeah, I feel kind of like, I don't know, I feel like a little 5-year-old, like "Huh? What?" Yeah.

Bob: [laughing]

Interviewer: It's pretty bad, trying to have conversations is almost impossible sometimes. I have to choose to face away from it.

Bob: [laughing]

Interviewer: Are there any other groups or offices that have a significant impact on the exterior enclosure?

Bob: Yes. The board of visitors.

Interviewer: Okay.

Bob: All designs go through the board of visitors. We don't go any further. They have to review everything, and there is a percentage, and it may be $20 \%$ of all buildings, the face has to be Hokie stone. That's in the University guidelines.

Interviewer: Okay.

Bob: But the board of visitors has to approve every exterior finish.

Interviewer: So they would definitely get like, yay or nay -

Bob: Yes. 
Interviewer: Okay.

Bob: And we went through several different drawings before we got one that the board of visitors actually liked. So this is kind of the package that they presented and went through where it was going to be located. So all of this was presented to us, and we made our comments, and then it went to the board of directors.

Interviewer: Okay.

Bob: I'm trying to find - they got into the drawings in this one. This goes way back. But then the building - even when the building - we had to take it from $73,000 \mathrm{ft}^{2}$ back down to - yeah, this was very early - but even at this stage, the board of visitors had a say. We had to kind of say, this is kind of where we want it to be, and they had to approve, "Yeah, that's where - that's fine. You can put it there." So this is our building here.

Interviewer: Okay.

Bob: So - but we had a lot of say in that, and ICTAS designed the medallions. See how it works? It goes on it -

Interviewer: ICTAS -

Bob: ICTAS designed those. We picked what we wanted to be represented and then it went back to the AE team's artist to go do the final - but we got to pick what we wanted on the exterior.

Interviewer: Okay. So we have the board of visitors, Juilie, ICTAS, and the AE all were significant - so they had - they were decision makers who significantly affected the exterior enclosure.

Bob: The exterior enclosure - right.

Interviewer: Okay, is there anyone else?

Bob: Not that I can think of right off.

Interviewer: Okay. Is there anyone else - 
Bob: Oh like, the University architect's office. It's just a UA office is what they call it. The University architect's office. They all say you have to weigh in.

Interviewer: Okay. Is there anyone else from the HVAC side of things?

Bob: And again I don't know all the players, I know Sam is the person that I work with. And again, we provide feedback on what our needs are, and then they - as far as they review the drawings after we get them passed that point.

Interviewer: You know these guys are in physical plant, right? Christine -

Bob: I don't really know who Christine is. Let's look him up. I'm just saying that he was one of the ones - I'm assuming he's the Sieman's representative. So -

Interviewer: Oh okay.

Bob: [typing] He may not be with the University.

Interviewer: That's fine. But Sam's -

Bob: Yeah, I don't know. Sam is - Sam, right.

Interviewer: He's from physical plant? Okay.

Bob: Yeah, I think they call it facility services now, but yeah.

Interviewer: Okay. Electrical system, superstructure, interior finishes.

Bob: And would you include ADA with interior finishes? Or does that -

Interviewer: No, that's a little, a little too specific at this point.

Bob: Operational issue - okay, okay.

Interviewer: At some point I would like to include all the way down to that level of detail, but since this is like the first stab at this I'm trying - I'm keeping things a little high-level.

Bob: Okay, that's fine. 
Interviewer: Yeah. Because what's going to happen is - what I'm ultimately going to do, when I get to my PhD, which hopefully will be the end of this summer, I'll start that - is I'm trying to actually create a computer model that optimizes investment in sustainability. But we want to include the social aspect of things, because that has a huge impact on - like, what is sustainable in a large part has to do with users and like, the whole process.

Bob: Because when you get into sustainability, there's another component, and that is another person along with Bill, who is a really, custodial - would be Sam who reviews all the areas for recycling, makes sure there's a recycling space available, and he also looks at traffic for waste coming in and out, making sure it's a good pathway and that type of thing.

Interviewer: Okay. Good, good. Very good. Yeah, so that's just how this ties in to what I'm doing next. Alright, so you don't have anyone else that you really wanted to add to this list necessarily?

Bob: Again, for the elevators, and that type thing, lifts, that would also be the ADA office, but for your purposes, if you're looking at sustainability primarily, Dan would be -

Interviewer: Oh I'm just looking at decision makers.

Bob: Yeah, right.

Interviewer: So.. they kind of view ADA as just like, that's a code that has to be complied with.

Bob: Right, right.

Interviewer: They don't really - they just make sure that the ADA requirements are met. So -

Bob: Right, and somebody else can make the decision on how they're met. I see, right, okay.

Interviewer: Yeah, yeah.

Bob: That's all I can think of right off.

Interviewer: That's - that's fine. That's perfect. 
Bob: There might be others, but I can't -

Interviewer: Just so that I can kind of get an idea of scale, for each of these that have more than one person, who would be like, the most influential. If you had a pick, who had like, the most influence or yes/no -

Bob: This would be the board of visitors.

Interviewer: Okay.

Bob: I mean, they don't make - we set down, we literally - the architects gave us a basic drawing and then ICTAS said yes, no, yes, no. Then when we got it to that point, the University architects office, they probably had the same level as we did, with yes, no, yes, no.

Interviewer: Okay.

Bob: But ultimately, it was the board of visitors that said, "Yes."

Interviewer: Alright -

Bob: And you're not looking at funding, so you're not going all the way up to BCOM level. Are you familiar with BCOM?

Interviewer: Yeah...

Bob: Okay. BCOM's more worried about the code and the budget. They're not so worried about design.

Interviewer: Yeah.

Bob: It does have to - BCOM's only role is going to make sure it's $69 \%$ efficient. All state buildings have to meet the efficiency rate of $69 \%$ as past that, they're not really worried about the design, as long as you've got the money to pay for it.

Interviewer: Okay, yeah.

Bob: I don't think that's the level you're looking for. 
Interviewer: I'm not - I don't think so at this point, because, I mean, really -

Bob: BCOM's a state agency, and more and more, as soon as we get Stephen trained on building codes, we're probably not going to be using BCOM a lot anymore anyway, because we're a charter now.

Interviewer: Oh, okay.

Bob: So, we're separating some from Richmond on our capital projects. They'll still have final say in the budgets because it's all still state funds. As far as the design, they'll get less and less involved.

Interviewer: Okay. Good to know. Good to know. Alright. For - well, lets see - for a superstructure it's pretty much going to be -

Bob: That's the engineer from the AE team.

Interviewer: The engineer, okay. And then interior finishes, who would you say has the most influence?

Bob: I'd say ICTAS actually.

Interviewer: ICTAS?

Bob: Again, we - John makes suggestions, the A\&E makes suggestions, but ultimately they defer to our decisions.

Interviewer: Okay, okay.

Bob: And just for the record, I was not here when these colors were picked. So if you like them -

Interviewer: [laughing]

Bob: I can't take credit. If you hate them, I'm not going to take credit. So, some people love them, some people hate them.

Interviewer: I understand. 
Bob: I'm just - because this carpet [laughing], it would not have been my choice. But that ultimately, what you have to deal with is whoever makes that decision within ICTAS, somebody else is going to like it or not like it, and so you try not to advertise who made the final decision. [laughing]

Interviewer: Exactly. Yeah. No one's going to know who's -

Bob: Oh, I mean I don't care, you know, I don't care. I just always give that disclaimer because when people moved in the labs there are bright yellow walls, and they're like, "Who picked these colors?" And I'm like, "Don't look at me! I love yellow and I love red, but I wouldn't have put them in the places they put them. It's hysterical."

Interviewer: Yeah, yeah. You're never going to keep everyone happy.

Bob: Oh, no, no.

Interviewer: It doesn't matter what you do.

Bob: We had some people that loved this furniture, and we - oh my gosh, on this building, on ICTAS I, I'Il say on the interior finishes, like the actual finishes - but then the furnishings, they hired an interior designer that was a part of the A\&E firm, and they would not listen to us, so we didn't really get what we wanted.

Interviewer: Uh, oh!

Bob: But she was just headstrong, so even John butted heads with her at times. But, so - we, we picked the colors, so we got to pick the colors, but the actual design wasn't exactly what we picked. But we had this book -

Interviewer: Oh my goodness.

Bob: So these are our finishes, so this is a big process. So we get this book and we sat down and we had to review everything, all the colors and the mock-up designs. So it was really hard to tell from this little bitty picture what we were actually getting. I mean, that really - I'm not familiar 
with this line before. Some of it I am. I know a lot of furniture lines. This is a Tec-Neon product, and this was the other thing that - there's a misfit between capital projects and maintenance.

Interviewer: Okay.

Bob: And I think by the - the University made a good move by moving all that under - there used to be - there was a maintenance division, there was a renovations division, and there was a capitol projects division. And that's where some of the misfits came in, and this is one thing I'm also the cofounder and co-chair of the campus-wide facilities managers network, and we have been taking things back to administration saying, "Look, when you're designing these buildings, you need to look at this. University doesn't clean glass. This building is full of glass, so that comes back to me to pay for and manage." So, they've heard us. They're now going to start cleaning glass I think twice a year. So the other thing is, I've recommended, and they're looking into this, where our group as a whole went to them and said, "You need to consider even the..." - what happens, the contractor, we spec what the - the University has a guideline of what the specifications are, for their handling, and that's - but then it's up to the contractor to interpret, and the interpretation isn't always the same. There is a huge cost associated with the multiple HVAC units they've picked, because all of them use different filters.

Interviewer: Ahh.

Bob: So we're trying to get them to standardize that. Just from a taxpayer's concern. Well, they don't really have anything to do with that. That's the preventive maintenance person here. We're trying to get them to standardize that a little better to try to cut some of the University costs. Because they can't - there's nowhere to store them.

Interviewer: Oh.

Bob: So, you have to have them, and there's multiple different kinds - where do you store them? So you run up a cost associated with storing them. So we're trying to get together from the maintenance management perspective and have more influence on the design, but we have not quite gotten there. Because it's up to the - you have to be so specific, with the specifications. 
Interviewer: Yeah.

Bob: So anyway, when they picked out all these colors, this is the book we get - and you can see here, tiny little sketches. We're not really sure what this stuff is and what it looks like until it actually gets here.

Interviewer: Right.

Bob: But this is what - we had to review this, and say yes, no, from the AE firm's interior designer. We are not hiring an interior designer for the next project.

Interviewer: Okay.

Bob: We vetoed that.

Interviewer: [laughing] Kind of helps to have a second building, different from the first.

Bob: But this is something that's a wonderful, wonderful tool. We have the O\&M manuals. I get those to manage the building, the preventive maintenance guy gets them, but we also get this book that says - so if we want to go back and buy this desk again, I know where it came from. I know what the finish is. And this has been - I did not have this on my other projects. I have done five projects at Tech.

Interviewer: Okay.

Bob: And so this has been the best thing from facilities management standpoint, to have an actual copy of the interior finishes.

Interviewer: Good to know. Good to know. Awesome. Alright, that's basically it. I don't have anything else for you. Thank you for your time.

Bob: Okay, well if you think of anything. Or if I think of anyone else that I may have missed - but again I don't know who all you're interviewing. 
Interviewer: I already interviewed, just so you know, I already interviewed several people in facilities. I just didn't want to say that, because I didn't want you to - I didn't want you to start assuming.

Bob: I hope it was consistent. [laughing]

Interviewer: Well that's exactly - that's exactly what I was looking for, to see if there was consistency, or to see if there was a different perspective.

Bob: Right, right.

Interviewer: And, for the most part, you're - you're pretty much $100 \%$ consistent with what they said.

Bob: And like I said, some of the players I may just not know.

Interviewer: Yeah, yeah. Which is - but the fact that you - for example, the board of visitors. They all said board of visitors, and we were all - we all were thinking it would be something else.

Bob: Right.

Interviewer: You know, so, this has just been a pretty - a pretty interesting process for us, because we thought that there might be someone like, from ICTAS, who like, makes a whole bunch of these decisions, but it turns out that it's not. It's really these other people groups.

Bob: And we make pretty much all decisions when it comes to lab design.

Interviewer: Right.

Bob: So, the lab design, actually the up-fits for the lab, that's all us, and then the engineers work to our design specifications, which is a large part of mine and David's job is designing the labs, and then we don't get so concerned with the codes. We expect them to fit our needs into whatever they need to - like, in this building we ended up with more fume hoods. We needed more fume hoods than the building could handle. So we had to go back and alter our plans a 
little bit. Unless there's something functionally like that, then they don't alter our layout of the labs.

Interviewer: Right.

Bob: That's all ICTAS. But when it gets to the façade, that's -

Interviewer: Yeah, that's kind of like -

Bob: A little bit ICTAS and -

Interviewer: Yeah, yeah. The specific lab makeup is kind of - because it will change over time.

Bob: Right, right.

Interviewer: You know, once a different lab group comes in, or if one lab group moves, then -

Bob: It can and can't. Like I said, if it's a fume hood, then that's pretty much there.

Interviewer: Right.

Bob: We don't have - this building's maxed out. There are no more fume hoods. Now we could take one and move it, like you said, from this lab to this lab, if the zone allows it. We have vertical zones in this building, so if it allows it, then yeah, you can do that. But yes, but the more permanent-type things would go back to the A\&E, or the board - the BOV. And even though we designed the medallions, the BOV had to approve those too.

Interviewer: Right, right. Which is why they're a key decision maker, they're the gatekeeper.

Bob: Right. 


\section{Appendix F: Interview Transcript B}

Interviewer: I'm not sure if this is going to work [the recording device], so we're going to see how it goes and you know, hopefully it will go well. Alright, okay - so to start off, I'm going to hand you this sheet and basically, it is a - the synopsis of a study that was done by the Department of Commerce. Are you familiar with the Uniformat system?

Nancy: Yep.

Interviewer: Okay, so what the Department of Commerce did is they went through and took a standard building - it was an 8-storey, office-type building; it had a footprint of about 8,000 $\mathrm{ft}^{2}$ and they estimated the cost for this building using the Uniformat, and so, when they finished calculating it, they went all the way to total installed cost. So they included their estimation of labor cost and an estimation of the contractor's markup, and then they tallied up how much each system cost, and these are the six systems that came up. This system corresponds with the bottom one, and then they just correspond on their way up. I don't have it in color, otherwise it would be a little bit -

Nancy: Yeah. I understand.

Interviewer: Clearer.

Nancy: Okay.

Interviewer: But basically what it is, is this system comprised approximately $17 \%$ or $18 \%$ of the total installed cost for that building. Alright? And then HVAC was, I think, $16.3 \%$ of that one building. And those - what's included in those systems is defined here. One important thing to note is exterior enclosure, that does not include the roof covering itself, okay? It's the roof covering like, the actual like, shingles if you were doing a sloped roof or malroofing or whatever. It's a separate category and it comprises about $0.5 \%$ of the cost of the building according to this study. 
Nancy: So it's basically the skin itself.

Interviewer: Yeah, it's basically the - the outside skin.

Nancy: Okay.

Interviewer: Superstructure starts from the foundation and goes up from there, doesn't include any site work or anything like that. Okay, so the first question is, in your opinion, do these systems also comprise - like, I mentioned that they comprised the largest section according to total installed cost - from your experience, do you think that they are also representative of the largest systems from an O\&M perspective?

Nancy: Yeah, I guess you want me to answer from my Virginia Tech experience, which is about, you know, almost 2 years now, or -

Interviewer: No, your -

Nancy: 30 years of -

Interviewer: 30 plus years.

Nancy: of private as well -

Interviewer: Yeah, everything... in this question.

Nancy: Yeah, I mean, okay so it's kind of a - are these - I guess your question is, are these the elements that typically make up the bulk of the -

Interviewer: Yeah.

Nancy: of the cost? I would say yes. I think the percentage varies depending on you know, the type of construction, you know, and certainly here at Virginia Tech with our Hokie stone and you know, metals, which are tending to be expensive now, and our move towards using special glass you know, that are energy reflective or absorption for LEED certification, all those things kind of contribute to the driving the percentage of exterior costs that we - we pay here, seems to be higher than what I have seen in industry, but, it's because of the look we're trying to 
achieve and the standards that we have on campus here, so. I'm trying to think - I mean, the other one that becomes significant, depending on where you are building, is your site preparation costs.

Interviewer: Okay.

Nancy: You know, if you're building in a big city for instance, and you know, you're restricted as far as what - the lay down space that you have, and how you have to stage deliveries and things like that, so those factors do contribute to higher costs if you're in an urban setting for instance, as opposed to a green field site where you've got lots of room, so.

Interviewer: Right.

Nancy: But, no I think you captured the main ones that I always see, of course, is the exterior and then the MEP, we call it, which is the mechanical-electrical systems - are the biggest cost typically, so.

Interviewer: If you're - if you were to try and break up the electrical system from the plumbing system from the mechanical system, are they - all three of those expensive from an O\&M standpoint, or is one kind of less expensive than the other ones?

Nancy: Well, when you say O\&M, you're talking about the actual operating costs once it's installed.

Interviewer: Yeah, once it's installed the operating and maintenance costs and then like, replacement cost, because at least in Virginia Tech's instance, and I hypothesize in most institutional owners - they design buildings for a very long life span, like 60 to 100 years.

Nancy: That's true.

Interviewer: So, obviously the HVAC system is going to have to be - something's going to happen to it in 60 to 100 years.

Nancy: You have to replace it at some point, yeah. 
Interviewer: Yeah.

Nancy: And that's usually in the 20 years, 25-year horizon you know, most equipment will have to be either rebuilt completely or replaced, so.

Interviewer: Whereas if you were to compare that to like, the exterior enclosure, like, you don't rebuild the walls obviously.

Nancy: Completely low maintenance there. [laughing]

Interviewer: I mean with Hokie stone you might have more maintenance, because I think they have to do lime treatments or something like that for some of the older buildings, I'm not sure.

Nancy: Yeah, but ideally you wouldn't, you're right, you wouldn't have a lot of expense on the exterior. Yeah, a lot depends on - these all look like conventional systems to me, too, now. I guess I'm thinking from my experience in the chemical industry and the semi-conductor industry; generally, reliability was a concern to us.

Interviewer: Okay.

Nancy: So we would build in, you know, extra motors and redundant control systems and things like that, and back up power and all that, so that we didn't have instances where systems would go down.

Interviewer: Okay.

Nancy: And that's because the cost of those losses, you know, the product you were making was huge, and you know, it would be millions of dollars a day that you would lose if you lost, you know, control of your temperature in the building, or electricity for some reason, so. So, we, you know, from my - my personal experience, I have seen a lot higher operating costs for some systems, mainly electrical actually -

Interviewer: Okay. 
Nancy: Because of the need to have either redundant chiller systems or back up power systems and you know, UPSs and all that kind of stuff, which are very expensive systems to try to install, especially if it's for the whole building, so. [laughing]

Interviewer: Right.

Nancy: And then the maintenance of those was huge as well, so. For conventional buildings, like an office building, I think you know, your example here -

Interviewer: Or are you thinking like a typical Virginia Tech building that should -

Nancy: Yeah. You know, a lot of those are done with service contracts and you know, competitive situations where you generally get a pretty good pricing for it, so. I haven't really personally I haven't managed a lot of operations and maintenance sort of activities. But, my focus on the design side has been to try to come up with ways to make the systems more reliable so you don't have those costs.

Interviewer: Okay.

Nancy: So I'm not sure I'm really answering your question, I can't, you know, in terms of quantifying where the dollars are in O\&M you know, certainly the electrical systems are probably where most of the expense is, just because things seem to wear out more or need to be tuned more often than, you know, mechanical systems. And mechanical stuff, you're you know, replacing a seal or realigning a pump or a motor or something like that. Those are relatively inexpensive operations compared to the cost of the equipment, so.

Interviewer: If you were to look at - so basically, if you were to look at each of those from a, like a whole system, those would constitute the majority of the -

Nancy: The ongoing costs.

Interviewer: The ongoing costs and maintenance costs for a single building? 
Nancy: Yeah, I would say so, certainly, you know, plumbing fixtures are relatively cheap to replace, and other things that are inside the buildings, so. Most of your expense is going to be in any rotating equipment.

Interviewer: Okay, alright. Excellent.

Nancy: I guess the other piece of that would be your - if you have a chill-water system or something like that, where you've got cooling towers and whatnot, it would be in the cost of the maintenance of the chemical treatment as well, you know. A lot of buildings - I was involved with high-purity water systems and very specialized gas or chemical treatment systems and things like that so, but those would be maybe the exception to a typical office building, so.

Interviewer: Okay. That's fine. Alright. Okay, before we go on, I'm going to - like I said when I started, and showed you this research information sheet and talked to you briefly on Friday my research is concerning identifying key decision makers for construction projects, so that eventually I can create a computer model that includes decision makers and how they make decisions. Because I'm trying to - I'm trying to make this model optimizing investment in sustainability, and in order to do that you have to kind of take into account - if you're going to make a realistic system, you need to take into account the particular decision making -

Nancy: You'll want to know what really happens -

Interviewer: Yeah - the decision making tendencies of the key decision makers. So, a key decision maker I've defined right here, and it's a person or a group who has the most influence on the systems characteristics, like the size or the color, you know, depending on what system you're talking about - and if it's a group that makes the decision, the group has to basically operate as a single entity, so like, I would consider most building committees a single entity, because they have to come up with a decision -

Nancy: They have to reach a consensus, right.

Interviewer: They have to - they have to reach a consensus.

Nancy: To move forward. 
Interviewer: To move forward. Okay, so I would consider them a single entity.

Nancy: Okay.

Interviewer: Okay, so if you were to think about the ICTAS II project, because we're only looking at a single project -

Nancy: Okay.

Interviewer: Alright? If you could tell me, or write down, the people who you think make decisions that affect each of the systems listed here that we went over on this high-system class chart.

Nancy: Okay. Well I would say for - for exterior enclosure, main decision makers as far as I was concerned would be the architect's office here.

Interviewer: Okay.

Nancy: Office of University Architect, OUA, and that would be Tyler, you know, as the architect, but he relies on input from his staff as well, you know, it comes from them as a consensus usually.

Interviewer: Okay.

Nancy: And then also probably our - not my immediate boss, but his boss, Amanda, is also directly involved with looking at elevations and you know, sort of the character of the building, we'll say, and the features that are evident in the elevations and the exterior. So I mean, those are the - those are the key folks, I mean there are others that are involved in helping with some of those decision, maybe trying to you know, sway them one way or the other, and that's mainly the folks that will be in the building, so. In the ICTAS's case, it would be ICTAS staff, and there was, you know, several of those folks that were always, you know, we would talk to them about it and see what they liked and didn't like, but the decision makers were either Tyler or, and Amanda together, so. 
Interviewer: Okay, one thing I forgot to mention, so we have key decision makers and then there are also what we would call like a rubber-stamp decision maker, like if you had - if you the example I'm going to use is, lets say you have an HVAC system, okay? And we'll assume for the purpose of this interview that all the codes and guidelines that Virginia Tech has is just a given, okay? So like, we're starting from that plane, alright? Within the bounds of the codes and guidelines, there's a certain amount of wiggle room and you'll have an HVAC consultant, lets say, who says, "Okay, I've understood your guidelines and," you know, the guidelines -

Nancy: The whole proposals -

Interviewer: Yeah, who'll come up with a couple different -

Nancy: What's good, and usually there's a few compromises, you know, that each one contains, right?

Interviewer: Right, so who - they would be - if they just made the - if they said, "We think you should go with this," and then it came to Virginia Tech and whoever was supposed to make the decision, or whoever had the authority to make the decision, just kind of goes, "Okay, you know, just whatever," and just like, rubber stamps it? Then the real decision maker would be the mechanical designer, or the HVAC consultant, okay? But if the consultant or architect -

Nancy: No, no I understand what you're saying, so. I think yeah, certainly it doesn't take one answer on the exteriors anyway. Between Tyler and Amanda, they will define what that building's going to look like.

Interviewer: Okay.

Nancy: And they get a lot of the input from the $A E$, different options to look at, but they ultimately make the selection.

Interviewer: Okay. Alright.

Nancy: And then you know, the users get a shot at it, but generally they have very little, I don't want to say useful input, but you know, [laughing] 
Interviewer: [laughing]

Nancy: Just uh, they kind of review it and say what they like and don't like about it, some of the features, but I mean they can't really - the overall character of the building really has to be something that Tyler and Amanda will approve, so.

Interviewer: Okay, excellent.

Nancy: On HVAC, hmm, that's a good question. Typically we - we have a mechanical utilities department, which is usually represented by $\underline{\operatorname{Stan}}$. Stan is one of the - I think he's assistant director or something of the, of that group, but if there's a question about an air handler or it's features or you know, some things that we can or cannot do with those systems, typically Stan will make that decision. You know, and he's - he will typically look to the architect to make a recommendation, but then he's going to yay or nay it so, and if he doesn't agree with it he's going to tell us what to do different. So yeah I would say he's the main decision maker there.

Interviewer: Okay.

Nancy: There's another fellow, Sam, who supports him. Sam's in a different group, but Sam's our lead senior mechanical engineer, and you know, I look to him - to him and Stan to kind of work things out, you know, and if they disagree they will either figure out between themselves you know, what the right answer is, and let us know, so. I would say Stan is probably the primary guy, but Sam's involved in a lot of the maybe, supporting decisions that go along with that, so.

Interviewer: Okay.

Nancy: Electrical... Electrical comes in two parts, really. You've got the main electrical service to the building, which I would call power distribution basically, and that would be Joseph. Joseph is over in the electric service. He's the engineering manager. And he's directly responsible - in fact, they supply that service, so the lines coming to a building, the transformer, there are some CTs and maybe a meter and that kind of stuff, all the front end stuff, getting to the building, is actually designed and supplied by electric service. So, you know the engineer will typically size 
that equipment for them, and get their concurrence, but they - they decide that piece of it. Once you get inside the building then, Dan is the senior electrical engineer. She actually sits over an electric service, I don't think she reports directly through them, but - something like that, you can find her in the system.

Interviewer: Yeah, I'll find her.

Nancy: Yeah, and she makes the decision as far as electrical gear inside the building, so questions about panels, elevators, emergency generators, you name it, electrical uses, lighting systems, dimming systems, all that kind of stuff she's got -

Interviewer: Alright.

Nancy: The review on those.

Interviewer: Perfect.

Nancy: Superstructure, that's typically the AE, whoever the engineer designer is. I mean, we will take a look at that, but as long as they are specifying you know, either concrete or steel, I don't think anybody really cares one way or the other [laughing]. So, interior finishes, you know that's actually something that the user - which in ICTASs case would be the ICTAS staff - are directly involved with. And they are held to that decision typically by John. John is our interior designer. So she works in that, and Amanda, she actually likes to review. Amanda.

Interviewer: Okay.

Nancy: You know, what we have come up with, but she typically will let John and the clients sort of work it out, you know, color schemes and finish, you know, quality and that sort of stuff. But Amanda does look at it to see, make sure we didn't do anything too weird. [laughing] So that's kind of a collaborative effort between the occupants of the building and John, primarily, but they will work with the AE - AE will typically come up with 2 or 3 alternatives and we'll kind of pick and choose amongst those.

Interviewer: Alright. So no neon green walls or anything like that. 
Nancy: Yeah, anything too crazy.

Interviewer: Bummer.

Nancy: Conveyance, what are you talking about there? That's -

Interviewer: I think that's - should be elevators, escalators, lifts -

Nancy: That would be Dan.

Interviewer: Okay.

Nancy: Dan as well. Those are kind of the key - key reviewers and decision makers.

Interviewer: Okay. Cool. For interior finishes, you would say - so basically ICTAS staff and John are - would be the two most -

Nancy: Yeah, but our process there is the AE will take a shot at it, and they'll create some boards, you know, they might have, I don't know, I'm not an architect - so they have, you know, the cool colors, and they have the warm colors, and different combinations of things and they kind of come up with a - sort of a character, you know, of the building.

Interviewer: Okay.

Nancy: And then we will say ah well, we like that, or we don't like - you know, there's usually about 2 or 3 meetings to go though and you know, kind of pick and choose, and then go back to work on it some more, come back with some more ideas, and, you know, eventually we end up with what they call a palate of all the interior finishes from carpet to countertops to colors and you know, that kind of stuff, so.

Interviewer: Okay.

Nancy: That'll be presented on some kind of a board, to show little samples of each thing and how they work together.

Interviewer: Okay. 
Nancy: But, yeah.

Interviewer: Alright, are there any other - as you were talking, did any other decision makers or groups that influence the decision making process -

Nancy: You know some project managers and [laughing] but, yeah, you know, we make them if nobody else does, but for these items anyway there's usually folks who are in place or you know, who feel that it's their decision, so. We let them do that, and then, anything else that's not covered I'll just decide myself or you know, talk to the users about it, so.

Interviewer: Okay, alright.

Nancy: But that's a pretty good start.

Interviewer: Cool. Well, I'm pretty sure that that is all that I have for you.

Nancy: Well that was pretty easy.

Interviewer: Yeah.

Nancy: So you're going to try to model what these guys are thinking as far as their decision process I guess.

Interviewer: Yeah, eventually what will hopefully happen is, we'll get this all figured out and then I'll have a framework or methodology that describes how this - or who - how to find the key decision makers. Then once they've been found, then I will go back and meet with them and come up with some sort of like, okay how do you make decision between these different systems you know, what are typically the most - what are the driving factors for you - I don't know what that's going to look like yet. That's going to be something that I'm going to have to think about next year. And there's going to be, I'm sure, all sorts of stuff that goes into that.

Nancy: Yeah, sounds like it will be interesting.

Interviewer: Yeah, no, I promise you I will be back. I will be bugging you [laughing] yes, again. Nancy: Yeah, that's fine. 
Interviewer: I really appreciate your time.

Nancy: Okay.

Interviewer: Do you have - are there any other final questions that you have?

Nancy: No, um, no. Give me a call if you have anything you want to talk about, or any ideas - I'm always - advice is always free, so.

Interviewer: [laughing]

Nancy: I'm happy to work with you.

Interviewer: Excellent, well thank you very much for your time.

Nancy: Okay, good luck to you.

Interviewer: Thanks. 


\section{Appendix G: Document Review Project Map}

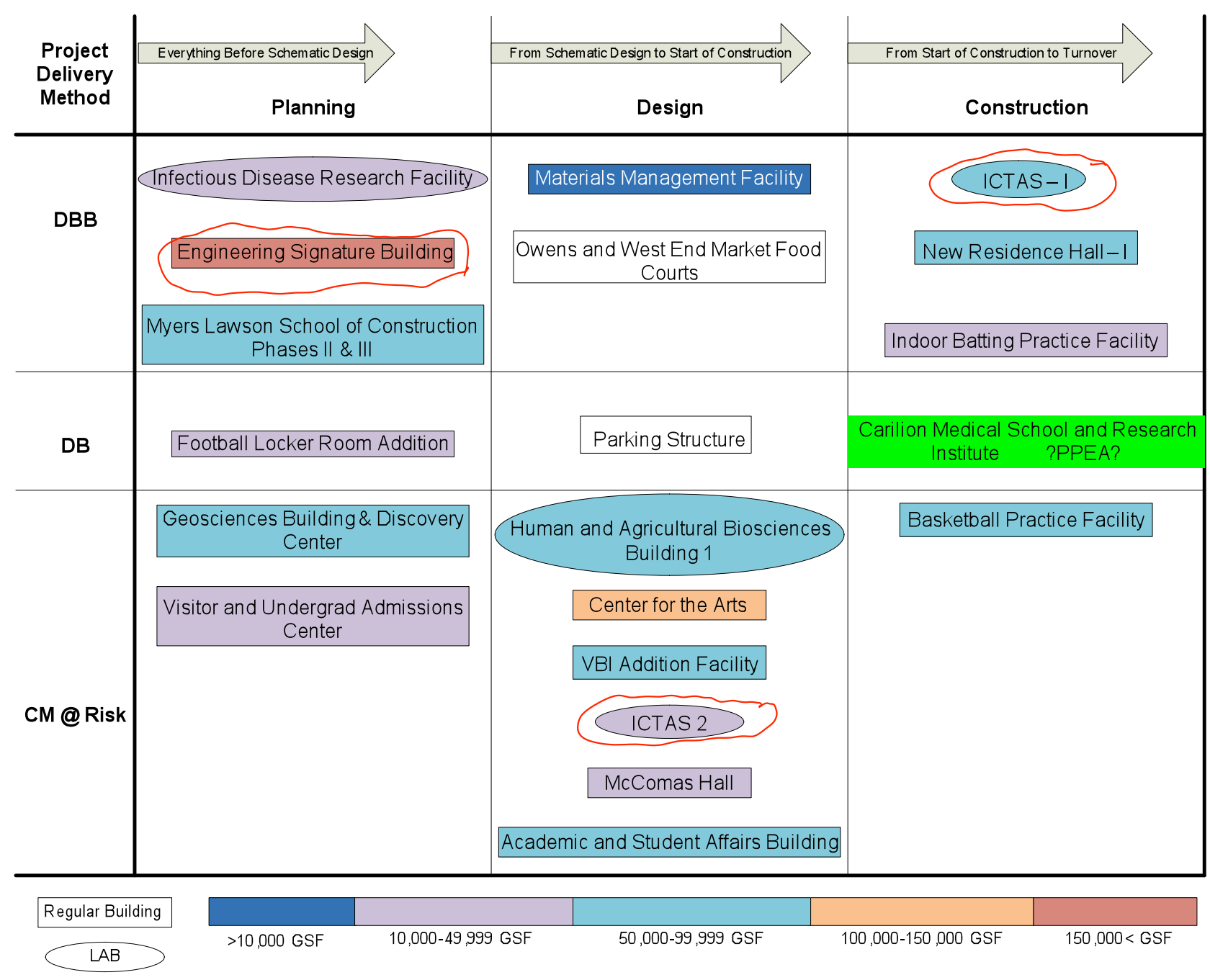

